\title{
Synthesis, Modular Composition, and Electrochemical Properties of Lamellar Iron SulfidesSynthesis, Modular Composition, and Electrochemical Properties of Lamellar Iron Sulfides
}

Noah E. Horwitz, Elena V. Shevchenko, Jehee Park, Eungje Lee, Jiaze Xie, Alexander S. Filatov, John Anderson

Submitted date: 16/01/2020 - Posted date: 20/01/2020

Licence: CC BY-NC-ND 4.0

Citation information: Horwitz, Noah E.; Shevchenko, Elena V.; Park, Jehee; Lee, Eungje; Xie, Jiaze; Filatov, Alexander S.; et al. (2019): Synthesis, Modular Composition, and Electrochemical Properties of Lamellar Iron SulfidesSynthesis, Modular Composition, and Electrochemical Properties of Lamellar Iron Sulfides.

ChemRxiv. Preprint. https://doi.org/10.26434/chemrxiv.10312529.v2

Transition metal chalcogenides with layered structures have emerged as promising materials for energy storage, catalysis, and electronics, among other areas. We have identified a new layered phase of iron sulfide containing interlayer solvated cations. We present an optimized synthesis for the Li+-containing material from an $\mathrm{Fe}(\mathrm{III})$ xanthate complex. Structure and composition data indicate the material consists of poorly-ordered iron sulfide layers separated by solvated cations. The lamellar spacing in these materials can be tuned by changing the identity of the cation. Furthermore, the lamellar spacing can also be reversibly tuned by the degree of solvation of the material. The material is electrically conductive and can serve as a pseudocapacitor with comparable performance to commercial materials such as $\mathrm{MnO}_{2}$. Furthermore, these materials also show promise as lithium or sodium ion battery cathodes with good capacity and reversibility.

File list (3)

Manuscript.pdf (1.11 MiB)

view on ChemRxiv • download file

SI.pdf (8.88 MiB)

view on ChemRxiv • download file

TOC.docx (186.23 KiB)

view on ChemRxiv • download file 


\section{ARTICLE}

\section{Synthesis, Modular Composition, and Electrochemical Properties of Lamellar Iron Sulfides}

Received 00th January 20xx Accepted 00th January 20xx

DOI: $10.1039 / \times 0 \times x 00000 x$

\author{
Noah E. Horwitz, ${ }^{a}$ Elena V. Shevchenko, ${ }^{b}$ Jehee Park, ${ }^{c}$ Eungje Lee, ${ }^{c}$ Jiaze Xie, ${ }^{a}$ Alexander S. Filatov, ${ }^{a}$ \\ John S. Anderson*a
}

\section{Introduction}

Layered structures containing transition metals demonstrate appealing properties for applications in energy storage and conversion. ${ }^{1,2}$ Layered transition metal oxides, in particular lithium cobalt oxide (LCO), have revolutionized the field of ion batteries, enabling the first commercial rechargeable Li-ion battery. ${ }^{3,4}$ They are also considered as promising candidates for Na-ion batteries. ${ }^{5}$ Other layered or monolayer transition metal chalcogenide materials have attracted significant attention for their promise in energy storage, energy conversion, electrocatalysis, and electronics. ${ }^{6-15}$ Layered iron chalcogenides, such as lamellar iron selenides, have been specifically targeted for applications in superconductivity. ${ }^{16-27}$ While layered iron sulfides are known in some minerals like tochilinite, there has been comparatively less work on synthetic approaches to generate layered iron sulfides as compared with their selenide congeners. This is despite the fact that iron sulfides have favorable properties, including the low cost and abundance of iron and sulfur, that make them promising candidates for batteries, supercapacitors, and superconductors. ${ }^{28-30}$

Synthetic protocols for layered iron chalcogenide materials typically proceed from direct combination of the elemental constituents with subsequent incorporation of interlayer

\footnotetext{
a. Department of Chemistry, University of Chicago, Chicago, Illinois 60637, United States

b. Center for Nanoscale Materials, Argonne National Laboratory, Argonne, Illinois 60439, United States

c. Chemical Sciences and Engineering Division, Argonne National Laboratory, Argonne, Illinois 60439, United States

Electronic Supplementary Information (ESI) available: Additional synthetic procedures, spectra, figures, and fitting parameters (PDF). See DOI: $10.1039 / x 0 x x 00000 x$
}

components by chemical or electrochemical intercalation. ${ }^{16,17,20,23,24,27}$ While there are also some limited examples of solvothermal syntheses, including some layered iron sulfides, ${ }^{26,31-37}$ we specifically were interested in discovering low-temperature routes to lamellar iron sulfides from well-defined molecular precursors. The thermal or solvothermal decomposition of Fe complexes with S-containing ligands such as dithiocarbamates and xanthates has previously been shown to be a convenient route to films or nanocrystals of iron sulfides such as greigite. ${ }^{38-45}$ We reasoned that these precursors could also provide a route to lamellar iron sulfide materials under appropriate conditions.

In this work, we report the synthesis of new lamellar iron sulfide phases from the single-source dithiocarbamate and xanthate precursors tris( $\mathrm{N}, \mathrm{N}$-diethyldithiocarbamato)iron(III) $\left(\mathrm{Fe}(\mathrm{DEDTC})_{3}\right)$ and tris(O-ethylxanthato)iron(III) $\left(\mathrm{Fe}(\mathrm{EX})_{3}\right)$ under solvothermal conditions in the presence of appropriate salts. Using this synthetic route, we show that cations can be intercalated between the iron sulfide layers. The intercalated cations have differing degrees of solvation depending on the treatment of the materials. The iron sulfide sheets themselves are composed predominantly of tetrahedral iron centers but have no long-range order. Finally, electrochemical data shows that the lamellar iron sulfide with $\mathrm{Li}^{+}$ions (1-Li) behaves as a pseudocapacitor, and initial data suggests that this material may also be useful for lithium and sodium ion batteries.

\section{Results and Discussion}

\section{Synthesis}

Lamellar iron sulfides can be obtained by heating $\mathrm{Fe}(\mathrm{DEDTC})_{3}$ with or without salt additives in dimethylformamide (DMF) for several days at $140^{\circ} \mathrm{C}$. The material synthesized in the presence 


\section{ARTICLE}

of 5 equivalents $\mathrm{LiCF}_{3} \mathrm{SO}_{3}$ is termed 1-Li. We are able to obtain new materials using 5 equivalents of $\mathrm{NaCF}_{3} \mathrm{SO}_{3}(\mathbf{1 - N a}), \mathrm{KCF}_{3} \mathrm{SO}_{3}$ (1-K), or $\quad \mathrm{TMAPF}_{6} \quad$ (tetramethylammonium hexafluorophosphate; 1-TMA) which we tentatively assign as isomorphous with 1-Li with $\mathrm{Li}^{+}$exchanged for the corresponding cations. In the absence of added salts, a material with a similar $X$-ray powder diffraction (XRPD) pattern is obtained; we suspect this material may contain $\mathrm{Me}_{2} \mathrm{NH}_{2}{ }^{+}$cations from thermal decomposition of DMF but have not investigated it further. The solvothermal decomposition of $\mathrm{Fe}(\mathrm{DEDTC})_{3}$ in DMF proceeds in low yield even after several days at reflux $(27 \%$ for $\mathbf{1}-\mathbf{L i}$, calculated using the empirical formula determined below). Following reports that metal xanthate complexes tend to have lower decomposition temperatures than the corresponding dithiocarbamates, ${ }^{46}$ we also prepared $\mathrm{Fe}(\mathrm{EX})_{3}$. Heating DMF solutions of $\mathrm{Fe}(\mathrm{EX})_{3}$ to $50{ }^{\circ} \mathrm{C}$ yielded 1-Li in good yield (91\%; Scheme 1), although this material is somewhat less ordered than that prepared from $\mathrm{Fe}(\mathrm{DEDTC})_{3}$ as indicated by a broader XRPD pattern.

The new lamellar phase we have observed was also found to form slowly upon extended heating of DMF solutions of $\left[\mathrm{Fe}_{4} \mathrm{~S}_{4}(\mathrm{SPh})_{4}\right]^{2-}$ salts. When higher temperatures were tested for the synthesis of our previously-reported coordination polymers of $\left[\mathrm{Fe}_{4} \mathrm{~S}_{4}\right]^{2+}$ and benzenedithiolate, ${ }^{47}$ this phase was detected as a minor contaminant, and increases in electrical conductivity of several orders of magnitude were observed. The poor ordering of the new sulfide phase when dry makes it difficult to detect in XRPD patterns of dry samples, and the presence of this or other poorly-ordered, conductive metal sulfide phases is highlighted as a potential source of error when measuring electrical conductivity of coordination polymers and metal organic frameworks with $\mathrm{S}$-based ligands. $\left[\mathrm{Fe}_{4} \mathrm{~S}_{4}\right]^{2+}$ clusters without bulky ligands are known to be oxidatively unstable, ${ }^{48}$ but the only report of a solid material as a degradation product of a similar cluster is a different phase containing chains of $\mathrm{Fe}_{4} \mathrm{~S}_{4}$ clusters linked by disulfide ions. ${ }^{49}$

\section{Structure and composition}

XRPD patterns of the iron sulfide materials measured as DMF suspensions in sealed capillaries with a variety of intercalated cations are presented in Figure 1a. Three major peaks are observed that can be assigned to (001), (002), and (003) reflections of separated iron sulfide layers in the formed lamellar structures. Consistent with this assignment, scanning electron microscopy (SEM) images of a dry sample of 1-Li show a sheet-like structure (Figure S3). Similar wrinkled sheets have been observed for related materials including $\mathrm{MoS}_{2}{ }^{50}$ and $2 \mathrm{D}$ metal-organic frameworks. ${ }^{51}$ Going from 1-Li to 1-Na and 1-K,

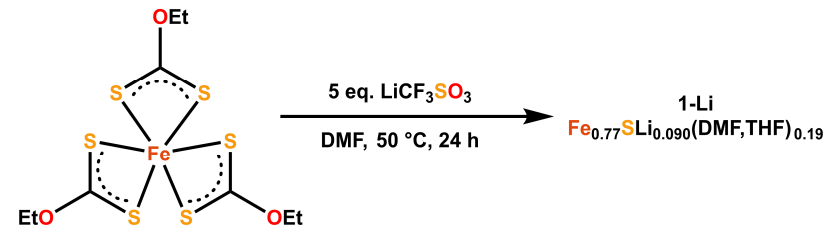

Scheme 1. Optimized synthesis of the lamellar iron sulfide 1-Li from Fe(EX) ${ }_{3}$.
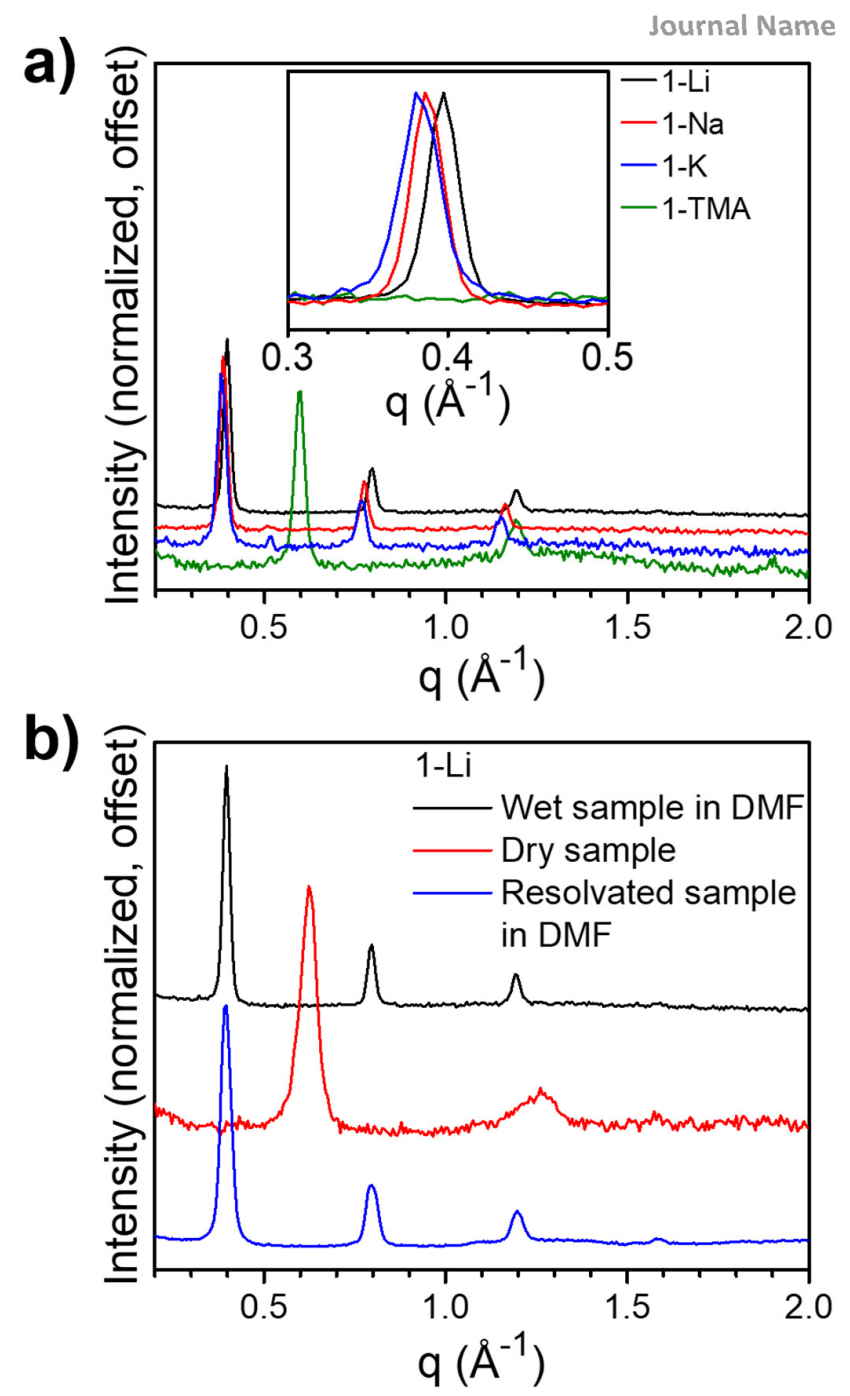

Figure 1. a) XRPD patterns of suspensions of 1-Li, 1-Na, 1-K, and 1-TMA in DMF, with inset showing the (001) lamellar diffraction peak. b) XRPD patterns of 1-Li as a suspension in DMF and following vacuum drying and resolvation with DMF.

the XRPD peak positions shift to smaller angles, showing a progression of interlayer distances consistent with the incorporation of these larger cations between the iron sulfide layers. The interlayer lamellar spacings are calculated from the

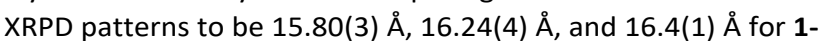
Li, 1-Na, and 1-K, respectively. It should also be mentioned that material synthesized with $\mathrm{LiCl}$ as an additive shows an identical XRPD pattern compared to material synthesized with $\mathrm{LiCF}_{3} \mathrm{SO}_{3}$ (1-Li; Figure S4). Upon drying, the XRPD patterns change as the peaks shift to larger angles, indicating that the spacing between the layers decreases, likely due to loss of solvation. For 1-Li, the lamellar spacing in the dry sample is approximately $10.5 \AA$. The peaks also broaden, showing that there is some loss of lamellar ordering in the dry material. Resolvation of 1-Li with DMF results in restoration of the original XRPD pattern with some slight broadening, showing that the solvation and desolvation of the material is largely reversible (Figure $1 b$ ).

1-TMA, containing the even-larger $\mathrm{TMA}^{+}$cation, surprisingly shows a lamellar spacing of 10.3(4) $\AA$ which is smaller than that 
in solvated 1-Li (Figure 1a). However, the XRPD pattern of this material does not change upon drying, in contrast to the materials containing alkali cations (Figure S5). This suggests that the changes upon drying are related to solvation of the cations between the iron sulfide layers, with the alkali cations being bound to several solvent molecules while $\mathrm{TMA}^{+}$is present as the bare ion. A similar phenomenon has been observed previously in lamellar $\mathrm{MoS}_{2}$ containing alkali and organic cations between sulfide layers. ${ }^{6}$

X-ray fluorescence (XRF) spectroscopy was performed to determine the Fe to $S$ ratio in 1-Li. A molar ratio of $0.77(2) \mathrm{Fe} / \mathrm{S}$ was found. Under the assumption that the material mostly consists of $\mathrm{Fe}^{2+}$ and $\mathrm{S}^{2-}$ ions, this $\mathrm{Fe} / \mathrm{S}$ ratio indicates a charge imbalance that can be resolved through 1) the presence of additional cations such as $\mathrm{Li}^{+}$or $\left.\mathrm{Me}_{2} \mathrm{NH}_{2}{ }^{+}, 2\right)$ the presence of some disulfide $\left(\mathrm{S}_{2}{ }^{2-}\right)$ ions, and/or 3 ) the presence of some $\mathrm{Fe}^{3+}$ ions.

The presence of additional cations is suggested by the changes in the XRPD pattern with different salts added during synthesis. To quantify the amount of $\mathrm{Li}^{+}$present, inductively coupled plasma mass spectrometry (ICP-MS) was performed on acid digests of 1-Li. A Li/Fe molar ratio of $0.118(7)$ was found, consistent with a preliminary empirical formula of $\mathrm{Fe}_{0.77} \mathrm{SLi}_{0.090}$. While the ICP-MS result shows conclusively that $\mathrm{Li}^{+}$is incorporated into the material when $\mathrm{LiCF}_{3} \mathrm{SO}_{3}$ is added during synthesis, the amount of $\mathrm{Li}^{+}$present is not enough to explain the charge imbalance. The FTIR spectrum of 1-Li does not show any features attributable to $\mathrm{N}-\mathrm{H}$ vibrational modes near $2400 \mathrm{~cm}^{-1}$, indicating that $\mathrm{Me}_{2} \mathrm{NH}_{2}{ }^{+}$(derived from thermal decomposition of the DMF synthesis solvent) is not present (Figure S14). Thus, the material likely contains some disulfide and/or $\mathrm{Fe}^{3+}$ ions.

Thermogravimetric analysis of dried 1-Li (TGA; Figure S11) shows mass loss of approximately $7 \%$ between 25 and $200{ }^{\circ} \mathrm{C}$ which is attributed to loss of THF and possibly water adsorbed during TGA sample preparation. A sharper mass loss step around $200^{\circ} \mathrm{C}$ is attributed to loss of DMF. ${ }^{22}$ Consistent with this assignment, the FTIR spectrum of 1-Li shows a band at $1656 \mathrm{~cm}$ ${ }^{1}$ from the $\mathrm{C}=\mathrm{O}$ stretch of DMF (Figure S14). An additional mass loss step around $500{ }^{\circ} \mathrm{C}$ likely represents decomposition of the material, possibly with release of sulfur. The TGA results suggest incorporation of approximately 2.1(2) solvent molecules per $\mathrm{Li}^{+}$ ion, resulting in an empirical formula of $\mathrm{Fe}_{0.77} \mathrm{SLi}_{0.090}(\mathrm{DMF}$, THF) 0.19 .

Further information about the structure of the iron sulfide layers was obtained from $\mathrm{Fe}$ K-edge X-ray absorption spectroscopy on 1-Li (XAS; Figure 2). The edge energy of 7119.7(4) eV is consistent with a mixture of $\mathrm{Fe}^{2+}$ and $\mathrm{Fe}^{3+}$ in the material. ${ }^{53}$ The absorption edge of 1-Li is about $1 \mathrm{eV}$ higher than that reported for mackinawite (all $\mathrm{Fe}^{2+}$ ) but similar to that of greigite (containing both $\mathrm{Fe}^{2+}$ and $\mathrm{Fe}^{3+}$ ) (Figure S7). ${ }^{54}$ Reported iron sulfide structures show octahedral or tetrahedral coordination at $\mathrm{Fe}$; the presence of a pre-edge feature near $7113 \mathrm{eV}$ indicates that at least some tetrahedral sites are present. ${ }^{55}$ Compared to mackinawite (tetrahedral coordination at Fe), the relative intensity of the pre-edge feature in 1-Li is lower, which might suggest the presence of some octahedral sites. The extended X-ray absorption fine structure (EXAFS) a)

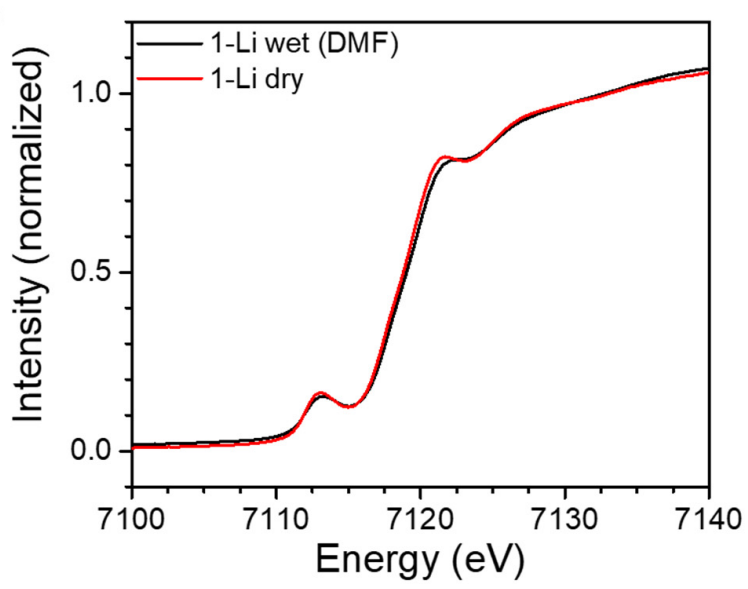

b)

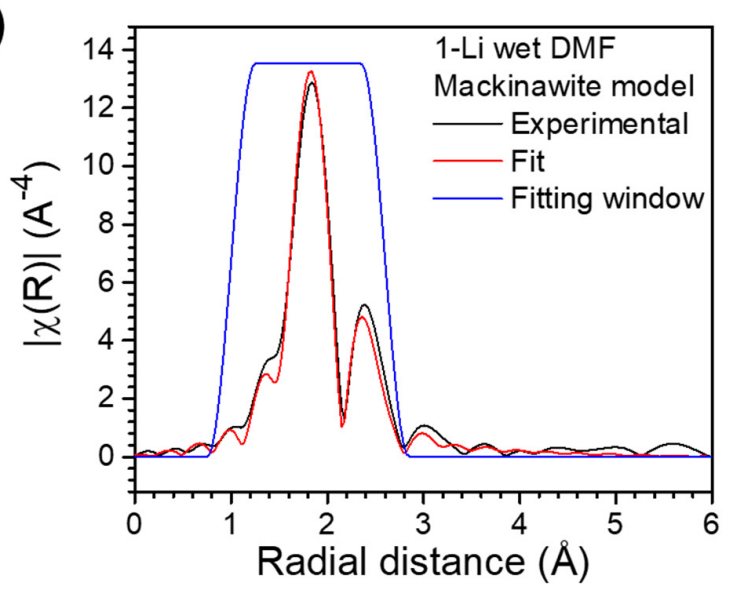

c)

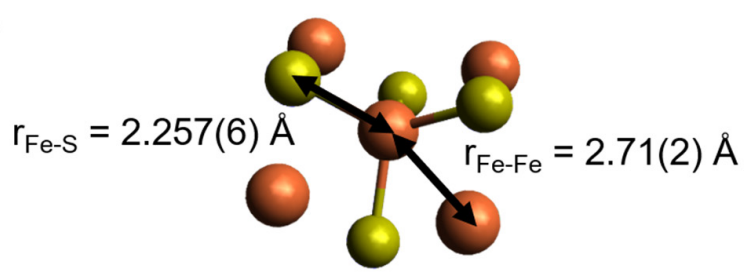

Figure 2. a) Near-edge XAS (XANES) data for 1-Li. b) R-space EXAFS data from 1-Li suspension in DMF, with fit to the structural model in c). c) Structural model based on mackinawite crystal structure, with fitted distances for 1-Li.

region can be fit to models derived from the crystal structures of smythite (octahedral coordination at Fe) and mackinawite (tetrahedral coordination at Fe) (Figure 2b, c, S8, S9). ${ }^{56-58}$ Satisfactory fits could not be obtained using models based on structures with $\mathrm{S}_{2}{ }^{2-}$ such as the iron disulfides pyrite and marcasite, suggesting most of the sulfur is present as $\mathrm{S}^{2-}$. The fitted Fe-S and Fe-Fe distances of 2.2257(6) and 2.71(2) $\AA$ respectively are closer to those in mackinawite $(2.256,2.598 \AA$ ) than to those in smythite $(2.498,2.860 \AA)$. . A structure similar to greigite containing both tetrahedral and octahedral Fe sites is more difficult to exclude on the basis of the EXAFS data, though we note that we were unable to obtain a good fit to the data using a model based on greigite. ${ }^{59}$ Together with the indication of some tetrahedral coordination from the pre-edge feature, the XAS data indicate that the Fe sites in the disordered iron 
sulfide layers are likely most similar to those in mackinawite or greigite. No significant difference was seen in either spectrum between dry and DMF-soaked samples (Figure 2a, S10), indicating that the layer structure is not significantly affected by solvation.

Taken together, these data point to a likely structural model for the materials: layers of poorly-ordered iron sulfide separated by cations with varying numbers of bound solvent molecules. These lamellar iron sulfide materials belong to a family of layered iron chalcogenides containing various interlayer atoms, including the aforementioned compounds investigated for superconductivity and magnetism. ${ }^{16,17,27,60,18,20-26}$ Many of these materials contain amine or hydroxide ligands bound to the intercalated cations; we speculate that this may help stabilize layered structures vs. bulk iron chalcogenides. Presumably the relatively strong binding of $\mathrm{Li}^{+}$to DMF or to a negatively charged iron sulfide layer in 1-Li could play a similar role and may explain why this material is not obtained from similar precursors under other conditions.

\section{Electronic structure}

${ }^{57} \mathrm{Fe}$ Mössbauer spectroscopy was used to assess the electronic environment of the Fe atoms in 1-Li. The Mössbauer spectrum of 1-Li at $80 \mathrm{~K}$ shows a quadrupole doublet with broad shoulders (Figure S13). The spectrum can be fit using two Fe sites with relative intensities of $0.85(2)$ and $1.15(4)$, isomer shifts of $0.428(3)$ and $0.446(6) \mathrm{mm} / \mathrm{s}$, and quadrupole splittings of $0.898(6)$ and $2.79(6) \mathrm{mm} / \mathrm{s}$ respectively (Table S2). These sites can be tentatively assigned to high-spin tetrahedral $\mathrm{Fe}^{3+}$ and high-spin tetrahedral $\mathrm{Fe}^{2+}$ respectively on the basis of the quadrupole splitting values. ${ }^{55}$ Charge balance calculations considering only $\mathrm{Fe}^{2+}, \mathrm{Fe}^{3+}, \mathrm{Li}^{+}$, and $\mathrm{S}^{2-}$ in the material give an $\mathrm{Fe}^{2+}$ to $\mathrm{Fe}^{3+}$ ratio of $1.0(2)$ to $1.0(2)$. This value is close to that estimated from Mössbauer spectroscopy (1:0.74), suggesting that the content of disulfide is at most a few mol. \%.

The spectrum of 1-Li is qualitatively different from those of mackinawite and greigite. Mullet et al. report three Fe sites in the Mössbauer spectrum of synthetic mackinawite: a singlet assigned as low-spin tetrahedral $\mathrm{Fe}^{2+}$ without neighboring $\mathrm{Fe}^{3+}$, a doublet assigned as tetrahedral $\mathrm{Fe}^{3+}$, and a doublet assigned as tetrahedral $\mathrm{Fe}^{2+}$ with neighboring $\mathrm{Fe}^{3+} .61$ As 1-Li contains similar amounts of $\mathrm{Fe}^{2+}$ and $\mathrm{Fe}^{3+}$, all of the $\mathrm{Fe}^{2+}$ sites are expected to have neighboring $\mathrm{Fe}^{3+}$ sites; thus this assignment is consistent with the lack of a singlet peak in the spectrum of 1 Li. The isomer shifts of both sites in 1-Li are similar, and their values are close to those in $\left[\mathrm{Fe}_{4} \mathrm{~S}_{4}\right]^{2+}$ clusters, which show significant electronic delocalization and an average Fe oxidation state of 2.5. ${ }^{62}$ Additionally, the isomer shifts in 1-Li correspond to an oxidation state of 2.5 according to an empirical relationship for tetrahedral Fe in sulfides. ${ }^{63}$ These observations may suggest that there is electronic delocalization in $\mathbf{1 - L i}$ as is observed in $\mathrm{Fe}_{4} \mathrm{~S}_{4}$ clusters.

Pressed pellets of 1-Li show an electrical conductivity of $0.4(2)$ $\mathrm{S} / \mathrm{cm}$ at room temperature. This relatively high value suggests that the material is either metallic or a heavily doped semiconductor. Optical absorption spectroscopy shows broad absorption in the UV and visible regions, tailing off in the nearIR region (Figure S12). A Tauc plot analysis ${ }^{64}$ suggests that the material is a semiconductor with an indirect band gap of $0.2 \mathrm{eV}$. The relatively high conductivity is likely a reflection of this small bandgap and presumably high doping due to the disordered layers and $\mathrm{Fe}^{3+}$ sites, although more sophisticated experiments would be required to concretely assign the mechanism of charge transport.

\section{Electrochemical properties}

The high electrical conductivity and layered structure of $\mathbf{1 - L i}$ might be conducive to electrical energy storage by allowing fast transport of electrons and ions. To test this hypothesis, cyclic voltammetry (CV) experiments were conducted on carbon paper electrodes coated with 1-Li. CV measurements conducted in $0.1 \mathrm{M} \mathrm{LiCF} \mathrm{SO}_{3} / \mathrm{DMF}$ electrolyte show a rectangular, pseudocapacitive response from approximately -0.8 to $-1.8 \mathrm{~V}$ vs. Fc/Fc (Figure 3). An average specific capacitance (for the 1Li component) of 90(10) F/g was measured with a scan rate of 1

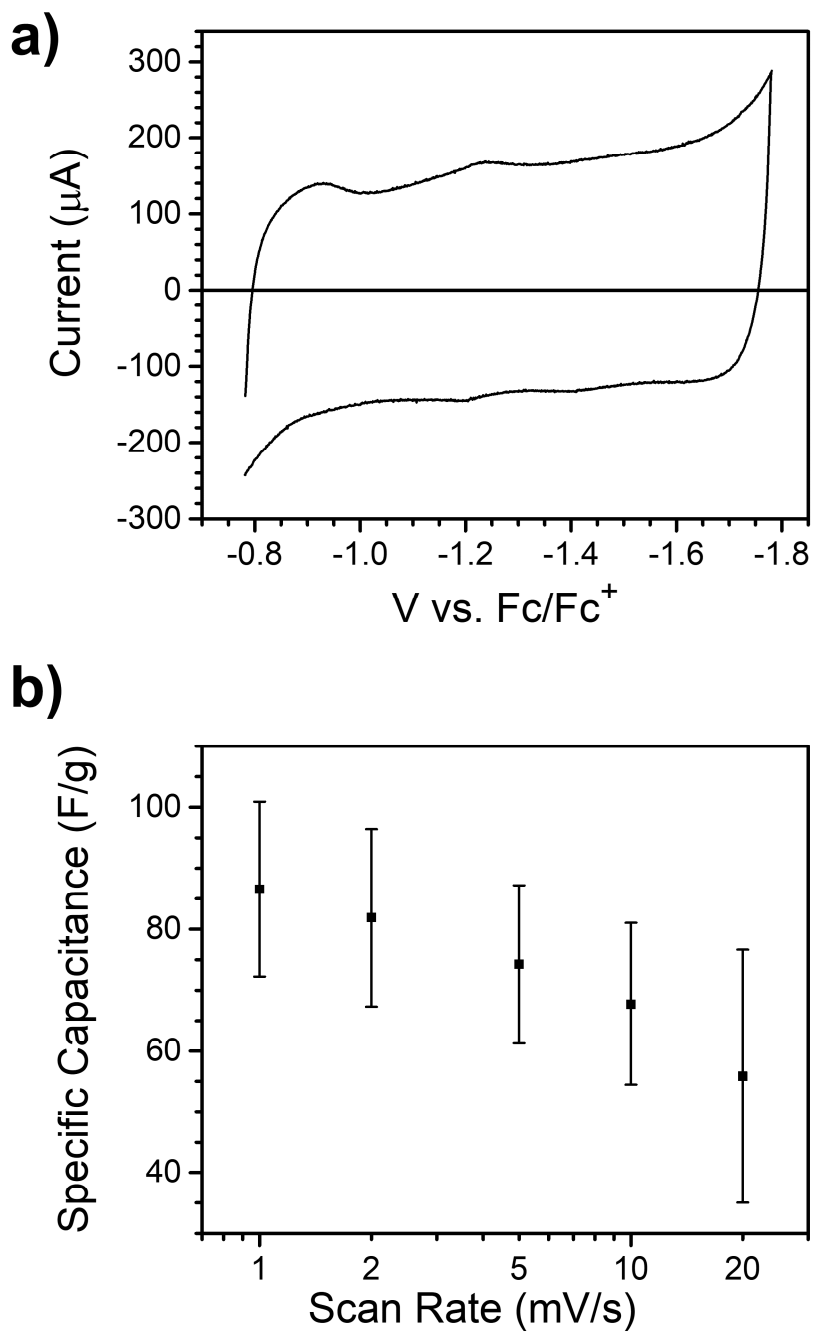

Figure 3. a) Representative cyclic voltammograms from electrode coated with 1-Li composite, in $0.1 \mathrm{M} \mathrm{LiCF}_{3} \mathrm{SO}_{3} / \mathrm{DMF}$ at $1 \mathrm{mV} / \mathrm{s}$ scan rate. b) Measured specific capacitance of 1-Li at different scan rates. 
$\mathrm{mV} / \mathrm{s}$. This value is comparable to those reported for other supercapacitor active materials, 6,49,65,66 suggesting that with further optimization, 1-Li might be useful in these applications. At more reducing and more oxidizing potentials, Faradaic features are observed near $-1.8 \mathrm{~V}$ and $-0.6 \mathrm{~V}$ vs. $\mathrm{Fc} / \mathrm{Fc}^{+}$(Figure $\mathrm{S} 16)$. This raises the possibility of Faradaic electrical energy storage in 1-Li in addition to the capacitive behavior described above. Composites of other iron sulfides with carbon-based materials have shown improved electrochemical performance compared to iron sulfides alone. ${ }^{67-72}$ As such, composite electrodes comprising 1-Li and multiwalled carbon nanotubes (CNTs) were tested as cathodes for lithium and sodium ion batteries. Electrochemical cycling tests show initial capacities of $450 \mathrm{mAh} / \mathrm{g}$ and $600 \mathrm{mAh} / \mathrm{g}$ for Li and Na respectively (Figure 4, S18-S21). The lithium ion cathode shows retention of $95 \%$ of the initial charging capacity after 16 charge/discharge cycles, though the capacity drops with faster charge/discharge rates (Figure $4 b$ ). The capacity retention for the sodium ion cathode is slightly lower ( $87 \%$ over 6 cycles).

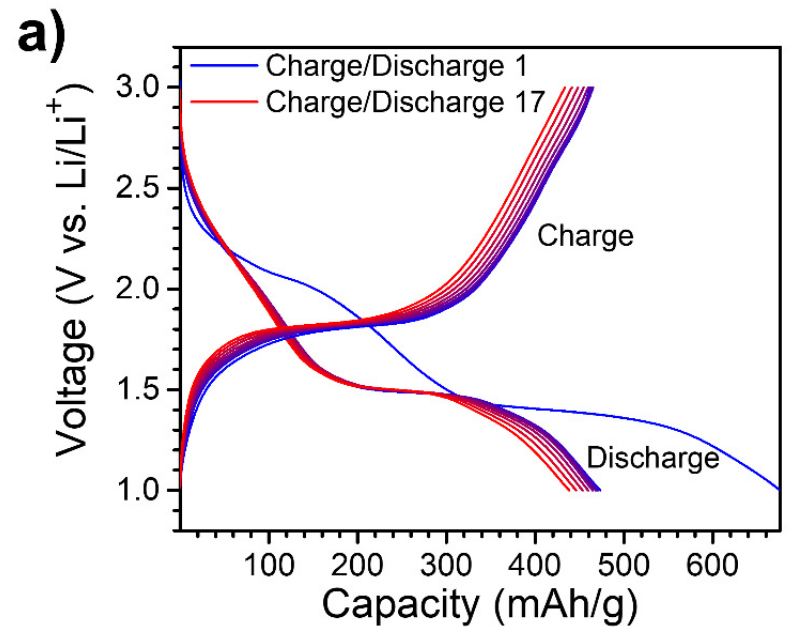

b)

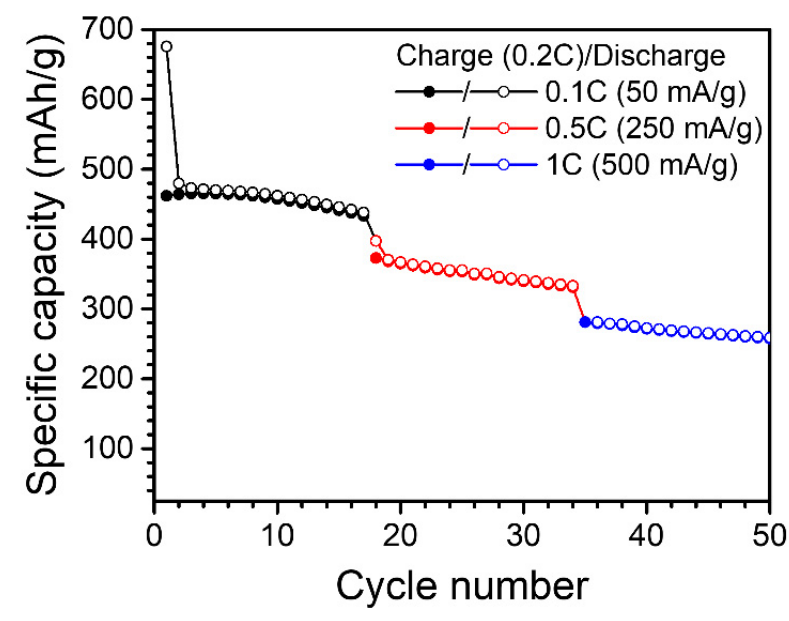

Figure 4. a) Charge/discharge curves at $0.1 \mathrm{C}$ rate and b) cycle stability at different rates for lithium ion battery cathode prepared with 1-Li.
The capacity in $\mathrm{Li}$ and $\mathrm{Na}$ electrochemical cycling tests are similar to those for other iron sulfides investigated for use in batteries, ${ }^{73-85}$ which typically behave as conversion-type electrodes. The first studies in this area were conducted with pyrite, which shows poor cycling stability. The capacity fading trends upon electrochemical cycling are similar to those observed for crystalline forms of iron sulfide (e.g. pyrite or mackinawite $)^{74,79,81}$ and can be attributed to the loss of sulfur active material by the dissolution of $\mathrm{Li}_{2} \mathrm{~S}_{\mathrm{n}}$ during discharge. ${ }^{86}$ While the detailed mechanism of the charge/discharge reactions is controversial, pyrite undergoes an irreversible phase change during the first discharge step. ${ }^{73,74,78}$ The initial capacity loss observed in 1-Li is common in conversion-type electrodes and may be due to a similar phase change and/or irreversible surface reactions such as electrolyte decomposition. ${ }^{81}$ The most similar materials that have been studied for battery applications are mackinawite microsheets, microspheres, and nanosheets. ${ }^{81,87}$ Interestingly, these authors also highlight the importance of strong ligands in forming the layered mackinawite phase and controlling its morphology. ${ }^{81}$ Lithium ion cathodes prepared from the mackinawite microsheets show a similar voltage profile to those with $\mathbf{1 - L i}$, suggesting a similar charge/discharge reaction mechanism. While the mackinawite microsheets show good cycling stability, the microspheres show lower capacity and stability; this result suggests that optimization of the morphology of the 1-Li electrodes is an important avenue for further study. Lithiation (discharge) of the material by a conversion reaction is associated with significant structural changes. ${ }^{88}$ However, 1-Li electrodes revealed a rather noticeable voltage plateau in the first discharge between 3 and $2 \mathrm{~V}$ that is not characteristic to crystalline forms of iron sulfide and may be indicative of ion intercalation. The dependence of the lamellar spacing on the solvation of this material motivates us to explore a ion-solvent co-intercalation mechanism utilized by graphite, which will require optimization of the electrolyte composition. ${ }^{89}$

\section{Conclusions}

We have identified a new lamellar phase of iron sulfide and proposed several approaches using different iron complexes for its synthesis. Structural and compositional data indicate that the material consists of poorly-ordered iron-sulfur layers separated by solvated ions. The composition and interlayer spacing can be tuned with different degrees of solvation and choice of intercalated cations. The identification of this phase as a byproduct in the syntheses of coordination polymers raises the possibility that poorly-ordered metal sulfide phases (which may be difficult to detect by XRPD) can occur as contaminants in studies of S-based metal-organic materials, where their high electrical conductivity can be problematic. Electrochemical studies on the Li-containing material 1-Li show voltage regions with both pseudocapacitive and Faradaic processes. Preliminary data indicates that this material may have potential for applications in supercapacitors and lithium or sodium ion batteries. The ability to prepare the material from low-cost precursors is advantageous for further studies in this area. 
These results highlight a new synthetic route to lamellar iron sulfides and lay the groundwork for more extensive studies of their electrochemical properties.

\section{Experimental}

\section{General Methods}

All manipulations with the iron sulfide products were performed under an inert atmosphere of dry $\mathrm{N}_{2}$ using a Schlenk line or MBraun UNIlab glovebox unless otherwise noted. ${ }^{1} \mathrm{H}$ NMR measurements were performed on Bruker DRX 400 or 500 spectrometers. Dimethylformamide (DMF), tetrahydrofuran (THF), and acetonitrile (MeCN) used in preparing the materials were initially dried and purged with $\mathrm{N}_{2}$ on a solvent purification system from Pure Process Technology. DMF was then passed through activated alumina before use. THF was stirred with liquid NaK alloy and then filtered through activated alumina and stored over $4 \AA$ molecular sieves. MeCN was stored over $4 \AA$ molecular sieves. $\mathrm{LiCF}_{3} \mathrm{SO}_{3}$ used for electrochemical measurements was trace metals grade $(99.95 \%$, Oakwood Chemical). Potassium ethyl xanthate (KEX) was synthesized following a previously reported procedure at $1 / 10$ scale. ${ }^{90}$ Dithio-p-urazine ${ }^{91}$ and $(\mathrm{TBA})_{2}\left[\mathrm{Fe}_{4} \mathrm{~S}_{4}(\mathrm{SPh})_{4}\right]^{92}$ were prepared as previously reported. All other chemicals were purchased from commercial sources and used as received. Unless otherwise stated, errors in all numerical values are estimated as the standard deviation of the average of three measurements on separate batches of material or are propagated from values calculated in this way.

\section{Synthetic Procedures}

\section{$\mathrm{Fe}(\mathrm{DEDTC})_{3}$ (tris(N,N-diethyldithiocarbamato)iron(III)):}

$\mathrm{Fe}(\mathrm{DEDTC})_{3}$ was synthesized following a reported procedure..$^{93}$ The ${ }^{1} \mathrm{H}$ NMR spectrum does not appear to have been reported previously; ${ }^{1} \mathrm{H}$ NMR spectroscopy was used along with XRPD to assess the purity of the compound. ${ }^{1} \mathrm{H} \mathrm{NMR}\left(400 \mathrm{MHz} \mathrm{CDCl}_{3}\right): \delta$ $40.3 \mathrm{ppm}$ (broad, 6H), 0.9 ppm (broad, 9H).

\section{$\mathrm{Fe}(\mathrm{EX})_{3}$ (tris(O-ethylxanthato)iron(III)):}

Note: this compound is temperature sensitive. An initial recrystallization attempt at $50{ }^{\circ} \mathrm{C}$ resulted in decomposition of the compound. All reaction and purification steps should be conducted at or below room temperature, and storage of the final product in a freezer is recommended.

$\mathrm{Fe}(\mathrm{EX})_{3}$ was prepared via an analogous procedure to $\mathrm{Fe}(\mathrm{DEDTC})_{3}$. Iron(III) chloride hexahydrate $(10.81 \mathrm{~g}, 40 \mathrm{mmol})$ was dissolved in $400 \mathrm{~mL} \mathrm{H}_{2} \mathrm{O}$ in an Erlenmeyer flask. In a separate flask, potassium ethyl xanthate $(19.23 \mathrm{~g}, 124 \mathrm{mmol})$ was dissolved in $400 \mathrm{~mL} \mathrm{H}{ }_{2} \mathrm{O}$. The solutions were combined with stirring, resulting in formation of a black precipitate. After 10 minutes at room temperature, the precipitate was collected by filtration and washed with $\mathrm{H}_{2} \mathrm{O}$. The crude solid was dissolved in DCM, transferred to a separatory funnel, and shaken with $\mathrm{H}_{2} \mathrm{O}$. The DCM layer was collected, dried over $\mathrm{Na}_{2} \mathrm{SO}_{4}$, and filtered. An equal volume of $\mathrm{MeOH}$ (approx. $400 \mathrm{~mL}$ ) was added and the solution concentrated on a rotary evaporator at room temperature until a solid began to precipitate. After storing the solution overnight in a freezer at $-35^{\circ} \mathrm{C}$, small black crystals of $\mathrm{Fe}(\mathrm{EX})_{3}$ were collected by filtration and washed with $\mathrm{MeOH}$ (15.27 g, 91\%). All reaction and purification steps were conducted in air, and the product was stored at $-35{ }^{\circ} \mathrm{C}$ in a $\mathrm{N}_{2}-$ filled glovebox. ${ }^{1} \mathrm{H} \mathrm{NMR}\left(400 \mathrm{MHz}, \mathrm{CDCl}_{3}\right): \delta 9.45 \mathrm{ppm}$ (broad q, $6 \mathrm{H}), 0.58 \mathrm{ppm}$ (broad t, 9H).

1-Li:

All reaction and isolation steps were performed under $N_{2}$. The isolated material is noted to be unstable in air, converting to a rust-colored solid after several hours. Additional synthetic methods for this material are presented in the Supporting Information.

\section{Method 1}

$\mathrm{Fe}(\mathrm{EX})_{3}(1.13 \mathrm{~g}, 2.7 \mathrm{mmol})$ and $\mathrm{LiCF}_{3} \mathrm{SO}_{3}(2.11 \mathrm{~g}, 13.5 \mathrm{mmol})$ were added to a $500 \mathrm{~mL}$ Schlenk flask. De-aerated DMF $(90 \mathrm{~mL})$ and a magnetic stir bar were added and the mixture stirred at room temperature until all solids dissolved. After approximately 10 minutes, the color of the solution changed from dark brown to orange. The flask was heated to $50^{\circ} \mathrm{C}$ for $24 \mathrm{~h}$ without stirring (a magnet was used to suspend the stir bar), resulting in formation of a dark solid. After cooling to room temperature, the reaction mixture was stirred for 10 minutes to dislodge solids from the walls of the flask. The suspended solid was withdrawn with a syringe, isolated via centrifugation, and washed $2 x$ with DMF $(40 \mathrm{~mL})$ and $3 x$ with THF $(20 \mathrm{~mL})$. Drying under vacuum afforded 1-Li as a black solid (289 mg, 91\%).

Method 2

$\mathrm{Fe}(\text { DEDTC })_{3}(75 \mathrm{mg} / \mathrm{vial}, 0.15 \mathrm{mmol} / \mathrm{vial})$ and $\mathrm{LiCF}_{3} \mathrm{SO}_{3}$ (117 $\mathrm{mg} / \mathrm{vial}, 0.75 \mathrm{mmol} / \mathrm{vial}$ ) were added to each of three vials along with DMF (15 mL each). The vials were sealed and shaken to dissolve all solids, then heated to $140{ }^{\circ} \mathrm{C}$ for 3 days. The resulting black solids were combined and isolated via centrifugation, washed $3 x$ with DMF $(6 \mathrm{~mL})$ and $3 x$ with THF $(6 \mathrm{~mL})$ to obtain 1Li (14 mg, 27\%).

\section{General procedure for 1-Na, 1-K, and 1-TMA:}

$\mathrm{Fe}(\mathrm{DEDTC})_{3}(25 \mathrm{mg}, 0.05 \mathrm{mmol})$ and salt additive $(0.25 \mathrm{mmol})$ were added to a vial along with DMF $(5 \mathrm{~mL})$. The vial was sealed and shaken to dissolve all solids, then heated to $140{ }^{\circ} \mathrm{C}$ for 3 days. The resulting black solid was isolated via centrifugation washed $2 x$ with DMF $(2 \mathrm{~mL}$ ) before preparation of XRPD samples as suspensions in DMF. The remaining material was washed $3 x$ with THF $(2 \mathrm{~mL})$ and dried under vacuum to prepare dry XRPD samples.

\section{X-ray Powder Diffraction Measurements}

$X$-ray powder diffraction measurements were performed on a SAXSLAB Ganesha equipped with a Xenocs GeniX3D $\mathrm{Cu}$ Ka source. Samples were loaded into 0.8-1.1 mm ID, 0.25 mm wall borosilicate capillaries and sealed with wax under $\mathrm{N}_{2}$. Samples were prepared dry, or as suspensions in DMF. Data reduction/integration was performed using Saxsgui software 
and a background correction for the capillary or capillary plus DMF solvent was applied.

\section{Scanning Electron Microscopy}

Scanning electron microscopy images were collected on a JEOL $7500 \mathrm{~F}$ microscope operating in secondary electron mode with 5 $\mathrm{kV}$ accelerating voltage.

\section{Digestion and ICP-MS Measurements}

Safety warning: Reaction of iron sulfides with nitric acid or other acids may produce toxic gases, including hydrogen sulfide and nitrogen dioxide. Digestions should be performed in a fume hood or with other adequate protection against toxic fumes. Samples for ICP-MS measurements were digested in trace metals grade conc. $\mathrm{HNO}_{3}$ ( $2 \mathrm{mg}$ sample/1 $\mathrm{mL}$ acid) overnight at room temperature in polypropylene centrifuge tubes. A small amount of insoluble solid assumed to be $S_{8}$ was observed. Samples were serially diluted with deionized ultrafiltered water and passed through $0.2 \mu \mathrm{m}$ PET syringe filters before measurement. ICP-MS data were obtained with an Agilent 7700x instrument and analyzed using ICP-MS Mass Hunter version $\mathrm{B} 01.03$. The samples were diluted in $2 \% \mathrm{HNO}_{3}$ matrix and analyzed with a ${ }^{159} \mathrm{~Tb}$ internal standard against a 12 -point standard curve over the range from $0.1 \mathrm{ppb}$ to $500 \mathrm{ppb}$. The correlation was > 0.9997 for all analyses of interest. Data collection was performed in Spectrum Mode with five replicates per sample and 100 sweeps per replicate.

\section{X-ray Fluorescence Measurements}

Samples were ground in a mortar and pestle and passed sequentially through 60 - and 120-mesh sieves. The sieved samples were placed in a polypropylene sample holder sealed with $4 \mu \mathrm{m}$ polypropylene film under $\mathrm{N}_{2}$.

XRF measurements were performed on a Rigaku NEX DE VS spectrometer using nitrogen as a balancing element. Samples from three batches were measured to obtain an average $\mathrm{Fe} / \mathrm{S}$ ratio.

\section{X-ray Absorption (XAS) Measurements}

Wet samples for XAS were prepared as slurries in DMF, blotted onto discs of ashless filter paper, and sealed in polyolefin bags. The sealed bags were then folded into Kapton tape. Dry samples for XAS were prepared by folding powder into Kapton tape. Xray near-edge absorption spectra (XANES) and X-ray absorption fine structure (XAFS) spectra were employed to probe the local environment around Fe. Data were acquired at the Advanced Photon Source at Argonne National Labs with a bending magnet source with ring energy at $7.00 \mathrm{GeV}$. Fe K-edge $(7712 \mathrm{eV})$ data were acquired at the MRCAT 10-BM beam line in transmission mode. The incident, transmitted and reference $X$-ray intensities were monitored using $\mathrm{N}_{2}$-filled ionization chambers. A metallic iron foil standard was used as a reference for energy calibration and was measured simultaneously with experimental samples. $\mathrm{X}$-ray absorption spectra were collected at room temperature.
Data collected was processed using the Demeter software suite ${ }^{94}$ by extracting the EXAFS oscillations $\chi(k)$ as a function of photoelectron wavenumber $k$. The theoretical paths were generated using FEFF6 and the models were done in the conventional way using the fitting program Artemis. The initial models were taken from crystal structures of mackinawite, smythite, greigite, pyrite, or marcasite. EXAFS data were modelled in R-space with k-weights of 1,2 and 3 until a satisfactory fit describing the system was obtained. Full fitting parameters are given in Table S1.

\section{Thermogravimetric Analysis (TGA)}

TGA was performed using a TA Instruments Discovery analyzer. Approximately $2 \mathrm{mg}$ of sample was loaded into a pre-tared $\mathrm{Pt}$ pan and measured under $\mathrm{N}_{2}$. Brief ( $<1$ minute) air exposure occurred during sample loading. Samples were measured from ambient to $700^{\circ} \mathrm{C}$ using a linear temperature ramp of $5^{\circ} \mathrm{C} / \mathrm{min}$. Solvent content was calculated using the total mass loss by the middle of the plateau region $\left(350^{\circ} \mathrm{C}\right)$. Due to overlap between mass loss steps, no attempt was made to separate contributions from THF and DMF in the calculations; the similar molecular weight of these solvents means this assumption has negligible impact on the calculated empirical formula and molecular weight for 1-Li.

\section{UV-visible-NIR Spectroscopy}

UV-visible-NIR absorption spectra were collected on a Shimadzu UV-3600 Plus spectrophotometer. Samples for absorption spectroscopy were prepared by Method 4 above on sapphire (0001). Coated substrates were placed into an $\mathrm{N}_{2}$-filled cell between two sapphire windows separated by a rubber spacer. The extinction spectrum of an uncoated sapphire substrate in the same holder was subtracted as a blank.

\section{Mössbauer Spectroscopy}

${ }^{57} \mathrm{Fe}$ Mössbauer spectra were measured at $80 \mathrm{~K}$ with zero applied magnetic field, using a constant acceleration spectrometer with a ${ }^{57} \mathrm{Co}$ on Rh source. Samples were encased in Paratone- $\mathrm{N}$ oil and placed in a polyethylene sample cup inside a $\mathrm{N}_{2}$-filled glovebox. Samples were frozen in liquid $\mathrm{N}_{2}$ immediately upon removal from the glovebox and kept cold while loading into the spectrometer. Spectra were analyzed using WMOSS software. Fitting parameters are given in Table S2.

\section{IR Spectroscopy}

Samples for infrared spectroscopy were prepared under $\mathrm{N}_{2}$ as $\mathrm{KBr}$ pellets. Infrared spectra were recorded on a Bruker Tensor II FTIR spectrometer with MCT detector operated at $77 \mathrm{~K}$. Data were processed and background corrected with OPUS software (version 7.5). An additional manual correction for scattering was also applied.

\section{Electrode Fabrication for Capacitance Measurements}


A solution of natural rubber latex in heptane (Elmer's No Wrinkle rubber cement) was diluted $10 x$ by volume with THF and sparged with $\mathrm{N}_{2}$. A sample of this diluted solution was dried under vacuum to determine the concentration of dissolved solids $(10.7 \mathrm{mg} / \mathrm{mL}$ ). 1-Li powder (43 $\mathrm{mg}$ ) was mixed with this solution $(0.5 \mathrm{~mL})$ to prepare a $90 \%$ by dry mass mixture of 1-Li with rubber cement. This mixture was sonicated in a sealed vial under $\mathrm{N}_{2}$ for 1 hour to disperse the solid and stirred before use. $1 \times 1 \mathrm{~cm}$ squares of conductive carbon paper (AvCarb MGL190) were dip-coated with the above slurry and dried in $\mathrm{N}_{2}$ and then under vacuum. The mass of each substrate was measured before and after coating to determine the mass of active material deposited (approx. 1-2 $\mathrm{mg} / \mathrm{sample}$ ). Uncoated substrates and substrates coated in only the $10 \%$ rubber solution were used as controls.

\section{Electrode Fabrication for Battery Measurements}

The electrodes were fabricated using c-grade multi-walled CNTs purchased from NanoTechLab ( $295 \%$ purity, $100 \mu \mathrm{m}$ long, diameter of CNTs is in the range of 5-30 nm) according to a modification of a previously reported approach. ${ }^{95} 2 \mathrm{mg}$ of CNTs were used for top and bottom layers and were dispersed in 50 $\mathrm{mL}$ solvent for $5 \mathrm{~min}$ under sonication. 1-Li was thoroughly ground under inert atmosphere prior to use. The active layer was obtained by mixing of $\sim 33 \mathrm{mg}$ of thoroughly grinded in the inert atmosphere lamellar iron sulfide with $\sim 2 \mathrm{mg}$ CNTs in anhydrous THF $(50 \mathrm{~mL})$ under sonication for $5 \mathrm{~min}$. Each layer was vacuum filtered using PTFE filter. The filtration station was $3.5 \mathrm{~cm}$ in diameter. Free-standing electrodes were further used without additional processing (no metal current collector, no polymer binders). The layered electrodes were annealed in a vacuum oven at $50^{\circ} \mathrm{C}$ for 2 hours.

\section{Electrochemical Measurements}

Electrical conductivity measurements were performed in a twocontact geometry at room temperature under $\mathrm{N}_{2}$. Samples were prepared as pressed pellets clamped between two brass electrodes (4.8 $\mathrm{mm}$ diam.) in a glass sleeve, allowing measurement of the sample thickness with calipers. Linear sweep voltammetry was conducted using a BASi Epsilon potentiostat/galvanostat, with the reference and counter electrode terminals connected to one electrode and the working electrode terminal to the other. The resulting data were fit to a straight line to obtain the sample resistance. All values have been measured in triplicate on separate batches.

Electrochemical experiments for capacitance measurements were performed using cyclic voltammetry (CV) on a BASi Epsilon potentiostat/galvanostat. The lamellar iron sulfide-coated or control substrates described above were used as the working electrode. A conductive carbon felt (Alfa Aesar 43200) counter electrode was used for all measurements. $\mathrm{An} \mathrm{Ag} / \mathrm{AgNO} \mathrm{N}_{3}(0.01$ $\mathrm{M}$ in $0.1 \mathrm{M} \mathrm{TBAPF}_{6} / \mathrm{MeCN}$ ) reference electrode with Vycor frit was used for all measurements. The reference electrode potential was measured vs. the $\mathrm{FeCp}_{2}{ }^{+} / \mathrm{FeCp}_{2}$ couple in a separate solution of the relevant electrolyte (with glassy carbon working electrode and platinum wire counter electrode) to correct for the liquid junction potential. Capacitance measurements were performed in triplicate on electrodes fabricated with different batches of material. Capacitance values were calculated from $\mathrm{CV}$ data by integration of the current in forward and reverse directions.

Battery tests were conducted on $1.4 \mathrm{~cm}$ diameter samples punched from $3.5 \mathrm{~cm}$ diameter samples obtained by filtration. The battery cycling tests were performed with the 2032 coin type cells with Li or $\mathrm{Na}$ metal foil as the counter electrodes and 1.2 M lithium hexafluorophosphate $\left(\mathrm{LiPF}_{6}\right)$ in ethylene carbonate/ethyl methyl carbonate (3:7 weight ratio) with 10 weight \% of fluoroethylene carbonate (FEC) or $1 \mathrm{M} \mathrm{NaPF}_{6}$ in ethylene carbonate/diethyl carbonate +2 weight $\%$ FEC, respectively. Half-cell cycles were operated at $0.1 \mathrm{C}$ rate $(50$ $\mathrm{mA} / \mathrm{g}$ ) between 1 and $3 \mathrm{~V}$ vs. $\mathrm{Li} / \mathrm{Li}^{+}$using an automated Maccor 2000 battery tester. The rate performance study on electrodes was conducted by cycling the coin cells between $1-3 \mathrm{Vvs}$. $\mathrm{Li}^{\prime} \mathrm{Li}^{+}$ at $0.1 \mathrm{C}, 0.5 \mathrm{C}$ and $1 \mathrm{C}$ charge/discharge rates. The coin cell tests were conducted in an environment chamber set at $30^{\circ} \mathrm{C}$.

\section{Conflicts of interest}

There are no conflicts to declare.

\section{Acknowledgements}

We thank Dr. David Zee for assistance with Mössbauer measurements. We thank Taokun Luo and Prof. Wenbin Lin for assistance with ICP-MS measurements. We thank Prof. Sarah King for helpful discussions. We thank Dr. John Katsoudas for assistance with XAS measurements at beamline 10-BM-A,B. This work was supported by the U.S. Department of Energy, Office of Science, Office of Basic Energy Sciences, under Award No. DESC0019215. MRCAT operations are supported by the Department of Energy and the MRCAT member institutions. Use of the Advanced Photon Source and work performed in part at the Center for Nanoscale Materials, both U.S. Department of Energy Office of Science User Facilities, was supported by the U.S. Department of Energy, Office of Science, under Contract No. DEAC02-06CH11357. Work by J.P. and E.L. was supported by the Advanced Battery Materials Research (BMR) Program of the U.S. Department of Energy, Energy Efficiency and Renewable Energy, Office of Vehicle Technologies. Parts of this work were carried out at the Soft Matter Characterization Facility of the University of Chicago.

\section{References}

1 V. Nicolosi, M. Chhowalla, M. G. Kanatzidis, M. S. Strano and J. N. Coleman, Science, 2013, 340, 1226419.

2 M. D. Smith, E. J. Crace, A. Jaffe and H. I. Karunadasa, Annu. Rev. Mater. Res., 2018, 48, 111-136.

3 N. Nitta, F. Wu, J. T. Lee and G. Yushin, Mater. Today, 2015, 18, 252-264.

4 U.-H. Kim, D.-W. Jun, K.-J. Park, Q. Zhang, P. Kaghazchi, D. Aurbach, D. T. Major, G. Goobes, M. Dixit, N. Leifer, C. M. 
Wang, P. Yan, D. Ahn, K.-H. Kim, C. S. Yoon and Y.-K. Sun, Energy Environ. Sci., 2018, 11, 1271-1279. Q. Liu, Z. Hu, M. Chen, C. Zou, H. Jin, S. Wang, S.-L. Chou and S.-X. Dou, Small, 2019, 15, 1805381. M. Acerce, D. Voiry and M. Chhowalla, Nat. Nanotechnol., 2015, 10, 313 M. M. Furchi, A. A. Zechmeister, F. Hoeller, S. Wachter, A. Pospischil and T. Mueller, IEEE J. Sel. Top. Quantum Electron., 2017, 23, 106-116. T. F. Jaramillo, K. P. Jørgensen, J. Bonde, J. H. Nielsen, S. Horch and I. Chorkendorff, Science, 2007, 317, 100-102. B. Hinnemann, P. G. Moses, J. Bonde, K. P. Jørgensen, J. H. Nielsen, S. Horch, I. Chorkendorff and J. K. Nørskov, J. Am. Chem. Soc., 2005, 127, 5308-5309. J. Xie, H. Zhang, S. Li, R. Wang, X. Sun, M. Zhou, J. Zhou, X. W. (David) Lou and Y. Xie, Adv. Mater., 2013, 25, 58075813. Y. Yu, S.-Y. Huang, Y. Li, S. N. Steinmann, W. Yang and L. Cao, Nano Lett., 2014, 14, 553-558. K. Kang, K.-H. Lee, Y. Han, H. Gao, S. Xie, D. A. Muller and J. Park, Nature, 2017, 550, 229. S. Xie, L. Tu, Y. Han, L. Huang, K. Kang, K. U. Lao, P. Poddar, C. Park, D. A. Muller, R. A. DiStasio and J. Park, Science, 2018, 359, 1131 LP - 1136.

B. Li, H. Wang, Y. Kawakita, Q. Zhang, M. Feygenson, H. L. Yu, D. Wu, K. Ohara, T. Kikuchi, K. Shibata, T. Yamada, X. K. Ning, Y. Chen, J. Q. He, D. Vaknin, R. Q. Wu, K. Nakajima and M. G. Kanatzidis, Nat. Mater., 2018, 17, 226-230. Y. Liu, Y. Li, H. Kang, T. Jin and L. Jiao, Mater. Horizons, 2016, 3, 402-421.

M. Burrard-Lucas, D. G. Free, S. J. Sedlmaier, J. D. Wright, S. J. Cassidy, Y. Hara, A. J. Corkett, T. Lancaster, P. J. Baker, S. J. Blundell and S. J. Clarke, Nat. Mater., 2012, 12, 15. T. Hatakeda, T. Noji, T. Kawamata, M. Kato and Y. Koike, J. Phys. Soc. Japan, 2013, 82, 123705.

R. Sun, S. Jin, L. Gu, Q. Zhang, Q. Huang, T. Ying, Y. Peng, J. Deng, Z. Yin and X. Chen, J. Am. Chem. Soc., 2019, 141, 13849-13857.

M. Sturza, J. M. Allred, C. D. Malliakas, D. E. Bugaris, F. Han, D. Y. Chung and M. G. Kanatzidis, Chem. Mater., 2015, 27, 3280-3290.

J. Guo, H. Lei, F. Hayashi and H. Hosono, Nat. Commun., 2014, 5, 4756

X. F. Lu, N. Z. Wang, H. Wu, Y. P. Wu, D. Zhao, X. Z. Zeng, X. G. Luo, T. Wu, W. Bao, G. H. Zhang, F. Q. Huang, Q. Z. Huang and X. H. Chen, Nat. Mater., 2014, 14, 325.

S. Hosono, T. Noji, T. Hatakeda, T. Kawamata, M. Kato and Y. Koike, J. Phys. Soc. Japan, 2014, 83, 113704.

A. M. Alekseeva, O. A. Drozhzhin, K. A. Dosaev, E. V Antipov, K. V Zakharov, O. S. Volkova, D. A. Chareev, A. N. Vasiliev, C. Koz, U. Schwarz, H. Rosner and Y. Grin, Sci. Rep., 2016, 6, 25624.

T. Hatakeda, T. Noji, K. Sato, T. Kawamata, M. Kato and Y. Koike, J. Phys. Soc. Japan, 2016, 85, 103702.

H. K. Vivanco and E. E. Rodriguez, J. Solid State Chem., 2016, 242, 3-21. X. Zhou, C. Eckberg, B. Wilfong, S.-C. Liou, H. K. Vivanco, J.
Paglione and E. E. Rodriguez, Chem. Sci., 2017, 8, 37813788.

M. Z. Shi, N. Z. Wang, B. Lei, C. Shang, F. B. Meng, L. K. Ma, F. X. Zhang, D. Z. Kuang and X. H. Chen, Phys. Rev. Mater., 2018, 2, 74801.

P. Knauth, Solid State Ionics, 2009, 180, 911-916. M. Tatsumisago and A. Hayashi, Int. J. Appl. Glas. Sci., 2014, 5, 226-235.

J. Lau, R. H. DeBlock, D. M. Butts, D. S. Ashby, C. S. Choi and B. S. Dunn, Adv. Energy Mater., 2018, 8, 1800933. M. Nath, A. Choudhury, A. Kundu and C. N. R. Rao, Adv. Mater., 2003, 15, 2098-2101.

Z.-A. Zang, H.-B. Yao, Y.-X. Zhou, W.-T. Yao and S.-H. Yu, Chem. Mater., 2008, 20, 4749-4755.

M. Wu, J. Rhee, T. J. Emge, H. Yao, J.-H. Cheng, S. Thiagarajan, M. Croft, R. Yang and J. Li, Chem. Commun., 2010, 46, 1649-1651.

G. A. Kakos, T. W. Turney and T. B. Williams, J. Solid State Chem., 1994, 108, 102-111.

J. T. Greenfield, S. Kamali, K. Lee and K. Kovnir, Chem. Mater., 2015, 27, 588-596.

J. T. Greenfield, C. Pak, S. Kamali, K. Lee and K. Kovnir, Chem. Commun., 2015, 51, 5355-5358.

C. Pak, S. Kamali, J. Pham, K. Lee, J. T. Greenfield and K. Kovnir, J. Am. Chem. Soc., 2013, 135, 19111-19114. W. Han and M. Gao, Cryst. Growth Des., 2008, 8, 10231030.

M. Afzaal, M. A. Malik and P. O'Brien, J. Mater. Chem., 2010, 20, 4031-4040.

M. Akhtar, M. A. Malik, F. Tuna and P. O'Brien, J. Mater. Chem. A, 2013, 1, 8766-8774. 2014, 67, 1693-1701.

S. Mlowe, D. J. Lewis, M. A. Malik, J. Raftery, E. B. Mubofu, P. O'Brien and N. Revaprasadu, Dalt. Trans., 2016, 45, 2647-2655.

S. Mlowe, S. S. Garje, T. Moyo and N. Revaprasadu, MRS Adv., 2016, 1, 235-240.

A. M. Paca and P. A. Ajibade, Mater. Chem. Phys., 2017, 202, 143-150. S. Mlowe, N. S. E. Osman, T. Moyo, B. Mwakikunga and N. Revaprasadu, Mater. Chem. Phys., 2017, 198, 167-176. N. Pradhan, B. Katz and S. Efrima, J. Phys. Chem. B, 2003, 107, 13843-13854.

N. E. Horwitz, J. Xie, A. S. Filatov, R. J. Papoular, W. E. Shepard, D. Z. Zee, M. P. Grahn, C. Gilder and J. S. Anderson, J. Am. Chem. Soc., 2019, 141, 3940-3951. J. Cambray, R. W. Lane, A. G. Wedd, R. W. Johnson and R. H. Holm, Inorg. Chem., 1977, 16, 2565-2571.

C. J. Pickett, S. K. Ibrahim and D. L. Hughes, Faraday Discuss., 2000, 116, 235-244.

Z. Yang, D. Gao, J. Zhang, Q. Xu, S. Shi, K. Tao and D. Xue, Nanoscale, 2015, 7, 650-658.

Y. Guo, W. Shi, H. Yang, Q. He, Z. Zeng, J. Ye, X. He, R. Huang, C. Wang and W. Lin, J. Am. Chem. Soc., 2019, 141, 17875-17883.

N. Getachew, Y. Chebude, I. Diaz and M. Sanchez-Sanchez, 
J. Porous Mater., 2014, 21, 769-773.

Y. T. He, J. T. Wilson and R. T. Wilkin, Geochim. Cosmochim. Acta, 2010, 74, 2025-2039.

H. Y. Jeong, K. Anantharaman, S. P. Hyun, M. Son and K. F. Hayes, Water Res., 2013, 47, 6639-6649. L. Que, Physical Methods in Bioinorganic Chemistry: Spectroscopy and Magnetism, University Science Books, 2000.

R. C. Erd, H. T. Evans Jr. and D. H. Richter, Am. Mineral., 1957, 42, 309-333.

A. R. Lennie, S. A. T. Redfern, P. F. Schofield and D. J. Vaughan, Mineral. Mag., 1995, 59, 677-683.

R. T. Downs and M. Hall-Wallace, Am. Mineral., 2003, 88, 247-250.

B. J. Skinner, R. C. Erd and F. S. Grimaldi, Am. Mineral., 1964, 49, 543-555.

D. Wu, Z. Guo, N. Liu, L. Zhou, Y. Mao, L. Wan, F. Sun and W. Yuan, Inorg. Chem. Commun., 2018, 91, 72-76.

S. Boursiquot, M. Mullet, M. Abdelmoula, J.-M. Génin and J.-J. Ehrhardt, Phys. Chem. Miner., 2001, 28, 600-611. H. Beinert, R. H. Holm and E. Münck, Science, 1997, 277, 653-659.

J. B. Goodenough and G. A. Fatseas, J. Solid State Chem., 1982, 41, 1-22.

B. D. Viezbicke, S. Patel, B. E. Davis and D. P. Birnie III, Phys. status solidi, 2015, 252, 1700-1710.

M. S. Javed, Z. Jiang, C. Zhang, L. Chen, C. Hu and X. Gu, Electrochim. Acta, 2016, 219, 742-750.

S.-M. Chen, R. Ramachandran, V. Mani and R. Saraswathi, Int. J. Electrochem. Sci., 2014, 9, 4072-4085.

X. Xu, T. Cai, Z. Meng, H. Ying, Y. Xie, X. Zhu and W.-Q. Han, J. Power Sources, 2016, 331, 366-372.

D. T. Tran, H. Dong, S. D. Walck and S. S. Zhang, RSC Adv., 2015, 5, 87847-87854.

L. Fei, Y. Jiang, Y. Xu, G. Chen, Y. Li, X. Xu, S. Deng and H. Luo, J. Power Sources, 2014, 265, 1-5.

S. Wang and J. Yu, Energies, 2016, 9.

G. X. Pan, F. Cao, X. H. Xia and Y. J. Zhang, J. Power Sources, 2016, 332, 383-388.

J. Liu, Y. Wen, Y. Wang, P. A. van Aken, J. Maier and Y. Yu, Adv. Mater., 2014, 26, 6025-6030.

R. Fong, J. R. Dahn and C. H. W. Jones, J. Electrochem. Soc. 1989, 136, 3206-3210.

S. S. Zhang, J. Mater. Chem. A, 2015, 3, 7689-7694.

Z. Hu, Z. Zhu, F. Cheng, K. Zhang, J. Wang, C. Chen and J. Chen, Energy Environ. Sci., 2015, 8, 1309-1316.

K. Takada, K. Iwamoto and S. Kondo, Solid State Ionics, 1999, 117, 273-276.

A. Douglas, R. Carter, L. Oakes, K. Share, A. P. Cohn and C.

L. Pint, ACS Nano, 2015, 9, 11156-11165.

A. Kitajou, J. Yamaguchi, S. Hara and S. Okada, J. Power Sources, 2014, 247, 391-395.

N. Voronina, H. Yashiro and S.-T. Myung, J. Mater. Chem. A, 2018, 6, 17111-17119.

H.-H. Fan, H.-H. Li, K.-C. Huang, C.-Y. Fan, X.-Y. Zhang, X.-L. Wu and J.-P. Zhang, ACS Appl. Mater. Interfaces, 2017, 9, 10708-10716.
C. Xing, D. Zhang, K. Cao, S. Zhao, X. Wang, H. Qin, J. Liu, Y. Jiang and L. Meng, J. Mater. Chem. A, 2015, 3, 8742-8749. W.-J. Yu, C. Liu, L. Zhang, P.-X. Hou, F. Li, B. Zhang and H.M. Cheng, Adv. Sci., 2016, 3, 1600113.

Y.-X. Wang, J. Yang, S.-L. Chou, H. K. Liu, W. Zhang, D. Zhao and S. X. Dou, Nat. Commun., 2015, 6, 8689.

Q. Li, Q. Wei, W. Zuo, L. Huang, W. Luo, Q. An, V. O. Pelenovich, L. Mai and Q. Zhang, Chem. Sci., 2017, 8, 160164.

K. Zhang, T. Zhang, J. Liang, Y. Zhu, N. Lin and Y. Qian, RSC Adv., 2015, 5, 14828-14831.

S. S. Zhang and D. T. Tran, J. Electrochem. Soc. , 2016, 163, A792-A797.

Q. Zhang, X. Yao, J. P. Mwizerwa, N. Huang, H. Wan, Z. Huang and X. Xu, Solid State lonics, 2018, 318, 60-64. S.-H. Yu, X. Feng, N. Zhang, J. Seok and H. D. Abruña, Acc. Chem. Res., 2018, 51, 273-281.

Y. Li, Y. Lu, P. Adelhelm, M.-M. Titirici and Y.-S. Hu, Chem. Soc. Rev., 2019, 48, 4655-4687.

C. C. Price and G. W. Stacy, Org. Synth., 1948, 28, 82. J. Sandström, Acta Chem. Scand., 1961, 15, 1575-1582. G. Christou, C. D. Garner, A. Balasubramaniam, B. Ridge, H. N. Rydon, E. I. Stiefel and W.-H. Pan, in Inorganic Syntheses, ed. J. P. J. Fackler, 1982, vol. 21. J. G. Leipoldt and P. Coppens, Inorg. Chem., 1973, 12, 2269-2274.

B. Ravel and M. Newville, J. Synchrotron Radiat., 2005, 12, 537-541.

E. Lee, R. A. Salgado, B. Lee, A. V Sumant, T. Rajh, C. Johnson, A. A. Balandin and E. V Shevchenko, Carbon N. Y., 2018, 129, 702-710. 
Supporting Information for:

\section{Synthesis, Modular Composition, and Electrochemical Properties of Lamellar Iron Sulfides}

Noah E. Horwitz, ${ }^{\text {a }}$ Elena V. Shevchenko, ${ }^{\mathrm{b}}$ Jehee Park, ${ }^{\mathrm{c}}$ Eungje Lee,,${ }^{\mathrm{c}}$ Jiaze Xie, ${ }^{\mathrm{a}}$ Alexander S. Filatov, ${ }^{\text {a John S. Anderson*,a }}$

${ }^{a}$ Department of Chemistry, University of Chicago, Chicago, Illinois 60637, United States

${ }^{b}$ Center for Nanoscale Materials, Argonne National Laboratory, Argonne, Illinois 60439, United States

${ }^{\mathrm{c}}$ Chemical Sciences and Engineering Division, Argonne National Laboratory, Argonne, Illinois 60439, United States

Correspondence to: jsanderson@uchicago.edu 


\section{Table of Contents}

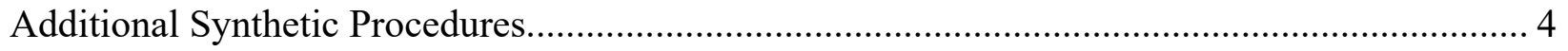

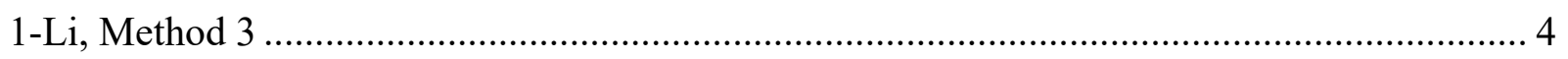

1-Li, Method 4 (to prepare films for UV-visible-NIR spectroscopy)....................................... 4

$1-\mathrm{Na}$

$1-\mathrm{K}$

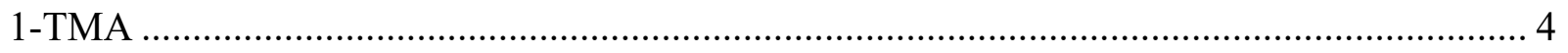

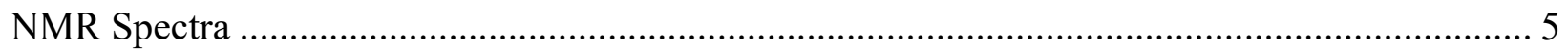

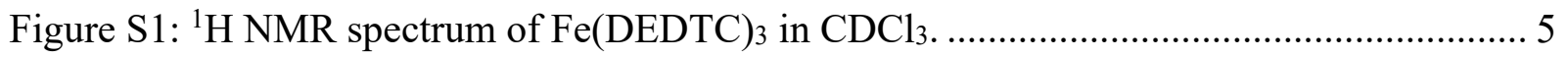

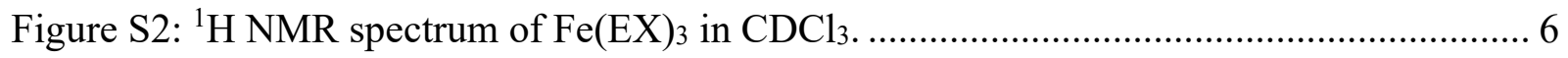

Scanning Electron Microscopy ……………....................................................................... 7

Figure S3. Representative SEM images of aggregates (a-b) and an isolated flake (d) of 1-Li. . 7

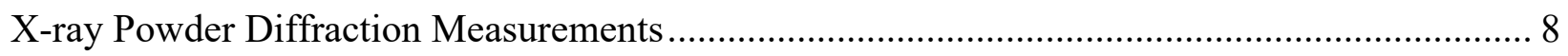

Figure S4: XRPD patterns of materials synthesized from $\mathrm{Fe}(\mathrm{EX})_{3}$ with different salt additives

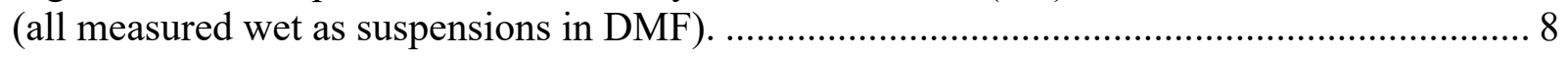

Figure S5: XRPD patterns of 1-TMA wet with DMF and dried. ............................................ 8

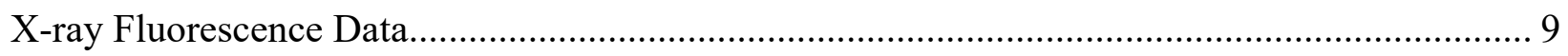

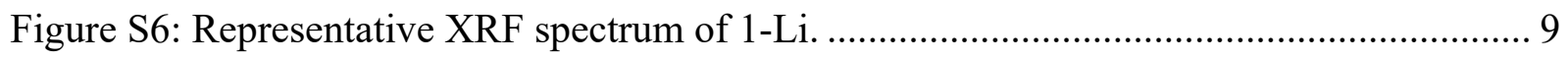

X-ray Absorption (XAS) Data and Fits ......................................................................... 9

Figure S7: Comparison of Fe K-edge XANES (first derivative) from 1-Li to literature data for mackinawite and greigite.................................................................................................. 9

Figure S8: EXAFS data from 1-Li (wet in DMF) with fit to mackinawite model presented in

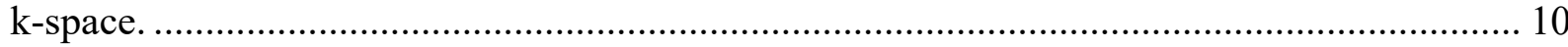

Figure S9: EXAFS data from 1-Li (wet in DMF) with a) R-space and b) k-space fits to

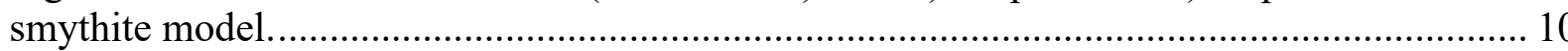

Table S1: EXAFS fitting parameters for 1-Li (wet in DMF) using structural models from

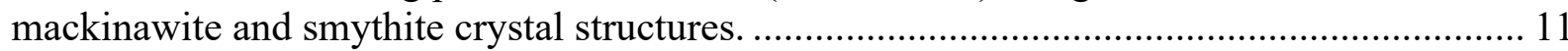

Figure S10: Comparison of EXAFS data from wet (DMF) and dry samples of 1-Li in a) R-

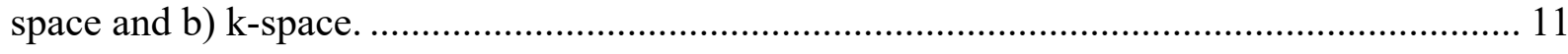

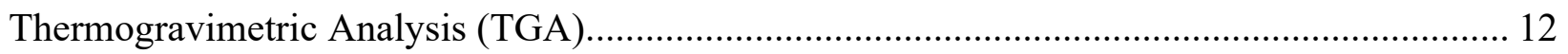

Figure S11: Thermogravimetric analysis data for three batches of 1-Li ................................ 12

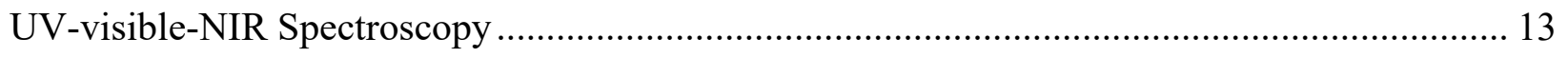

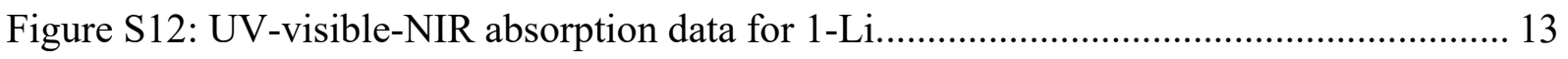

Mössbauer Spectroscopy ............................................................................................... 14

Figure S13: ${ }^{57} \mathrm{Fe}$ Mössbauer spectrum of 1-Li collected at $80 \mathrm{~K}$ with fit to a two site model. 14

Table S2: Mössbauer fitting parameters. ......................................................................... 14 


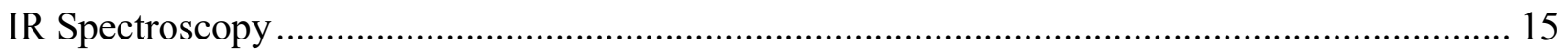

Figure S14: FTIR spectrum of 1-Li prepared as a $\mathrm{KBr}$ pellet. ............................................. 15

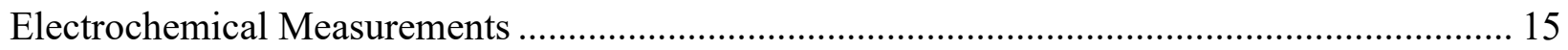

Figure S15. Cyclic voltammograms ( $1 \mathrm{mV} / \mathrm{s}, 0.1 \mathrm{M} \mathrm{LiCF}_{3} \mathrm{SO}_{3}$ in $\left.\mathrm{DMF}\right)$ of carbon paper electrode coated with $1-\mathrm{Li}+10 \%$ rubber slurry and control electrodes.................................. 15

Figure S16: Cyclic voltammetry data for 1-Li composite electrode in $0.1 \mathrm{M} \mathrm{LiCF}_{3} \mathrm{SO}_{3} / \mathrm{DMF}$

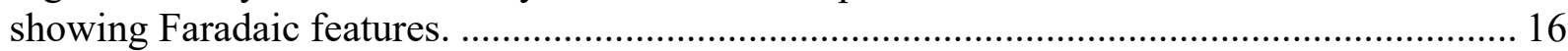

Figure S17: Cyclic voltammograms of the same 1-Li composite electrode in different

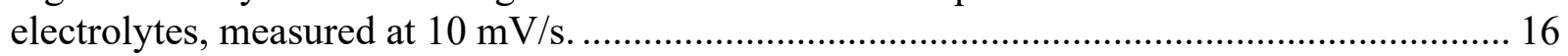

Figure S18: dQ/dV plot for 1-Li lithium ion cathode half cell tests at 0.1C......................... 17

Figure S19: Charge/discharge curves for 1-Li sodium ion cathode half cell tests................... 17

Figure S20: dQ/dV plot for 1-Li sodium ion cathode half cell tests...................................... 18

Figure S21: Cycling stability of 1-Li sodium ion cathode in half cell tests............................ 18 


\section{Additional Synthetic Procedures}

\section{1-Li, Method 3}

$\mathrm{Fe}(\mathrm{DEDTC})_{3}(25 \mathrm{mg}, 0.05 \mathrm{mmol})$ and $\mathrm{LiCF}_{3} \mathrm{SO}_{3}(39 \mathrm{mg}, 0.25 \mathrm{mmol}$ ) were added to a vial and dissolved in DMF (2.5 mL). In a separate vial, dithio-p-urazine (15 mg, $0.1 \mathrm{mmol})$ was dissolved in DMF $(2.5 \mathrm{~mL})$. The solutions were combined and heated in a sealed vial to $100{ }^{\circ} \mathrm{C}$ for $24 \mathrm{~h}$. The resulting black solid was isolated via centrifugation, washed $2 \mathrm{x}$ with DMF $(2 \mathrm{~mL})$ and $3 \mathrm{x}$ with THF (2 mL) to obtain 1-Li ( $7 \mathrm{mg}$, quant.).

1-Li, Method 4 (to prepare films for UV-visible-NIR spectroscopy)

$\mathrm{Fe}(\mathrm{EX})_{3}(17 \mathrm{mg}, 0.04 \mathrm{mmol})$ and $\mathrm{LiCF}_{3} \mathrm{SO}_{3}(31 \mathrm{mg}, 0.2 \mathrm{mmol})$, and DMF (4 mL) were mixed and the resulting solution divided between two $4 \mathrm{~mL}$ vials. A sapphire substrate was added to each vial and the vials were maintained at room temperature for 2 days. During this time, a film of dark solid formed on the vial walls and the surfaces of the substrates. The substrates were washed $2 \mathrm{x}$ with DMF $(2 \mathrm{~mL})$ and $2 \mathrm{x}$ with THF $(2 \mathrm{~mL})$ before being dried under vacuum.

\section{$1-\mathrm{Na}$}

$\mathrm{Fe}($ DEDTC) 3 (25 mg, $0.05 \mathrm{mmol})$ and $\mathrm{NaCF}_{3} \mathrm{SO}_{3}(43 \mathrm{mg}, 0.25 \mathrm{mmol}$ ) were added to a vial along with DMF ( $5 \mathrm{~mL}$ ). The vial was sealed and shaken to dissolve all solids, then heated to $140{ }^{\circ} \mathrm{C}$ for 3 days. The resulting black solid was isolated via centrifugation, washed $2 \mathrm{x}$ with DMF (2 mL) and $3 \mathrm{x}$ with THF $(2 \mathrm{~mL})$ to obtain 1-Na.

$1-\mathrm{K}$

$\mathrm{Fe}(\mathrm{DEDTC}){ }_{3}(25 \mathrm{mg}, 0.05 \mathrm{mmol})$ and $\mathrm{KCF}_{3} \mathrm{SO}_{3}(47 \mathrm{mg}, 0.05 \mathrm{mmol})$ were added to a vial along with DMF ( $5 \mathrm{~mL})$. The vial was sealed and shaken to dissolve all solids, then heated to $140{ }^{\circ} \mathrm{C}$ for 3 days. The resulting black solid was isolated via centrifugation, washed $2 \mathrm{x}$ with DMF $(2 \mathrm{~mL})$ and $3 \mathrm{x}$ with THF $(2 \mathrm{~mL})$ to obtain $\mathbf{1 - K}$.

\section{1-TMA}

Fe(DEDTC)3 (25 mg, $0.05 \mathrm{mmol})$ and TMAPF6 $(55 \mathrm{mg}, 0.05 \mathrm{mmol})$ were added to a vial along with DMF $(5 \mathrm{~mL})$. The vial was sealed and shaken to dissolve all solids, then heated to $140{ }^{\circ} \mathrm{C}$ for 3 days. The resulting black solid was isolated via centrifugation, washed $2 \mathrm{x}$ with DMF $(2 \mathrm{~mL})$ and $3 \mathrm{x}$ with THF $(2 \mathrm{~mL})$ to obtain 1-TMA. 


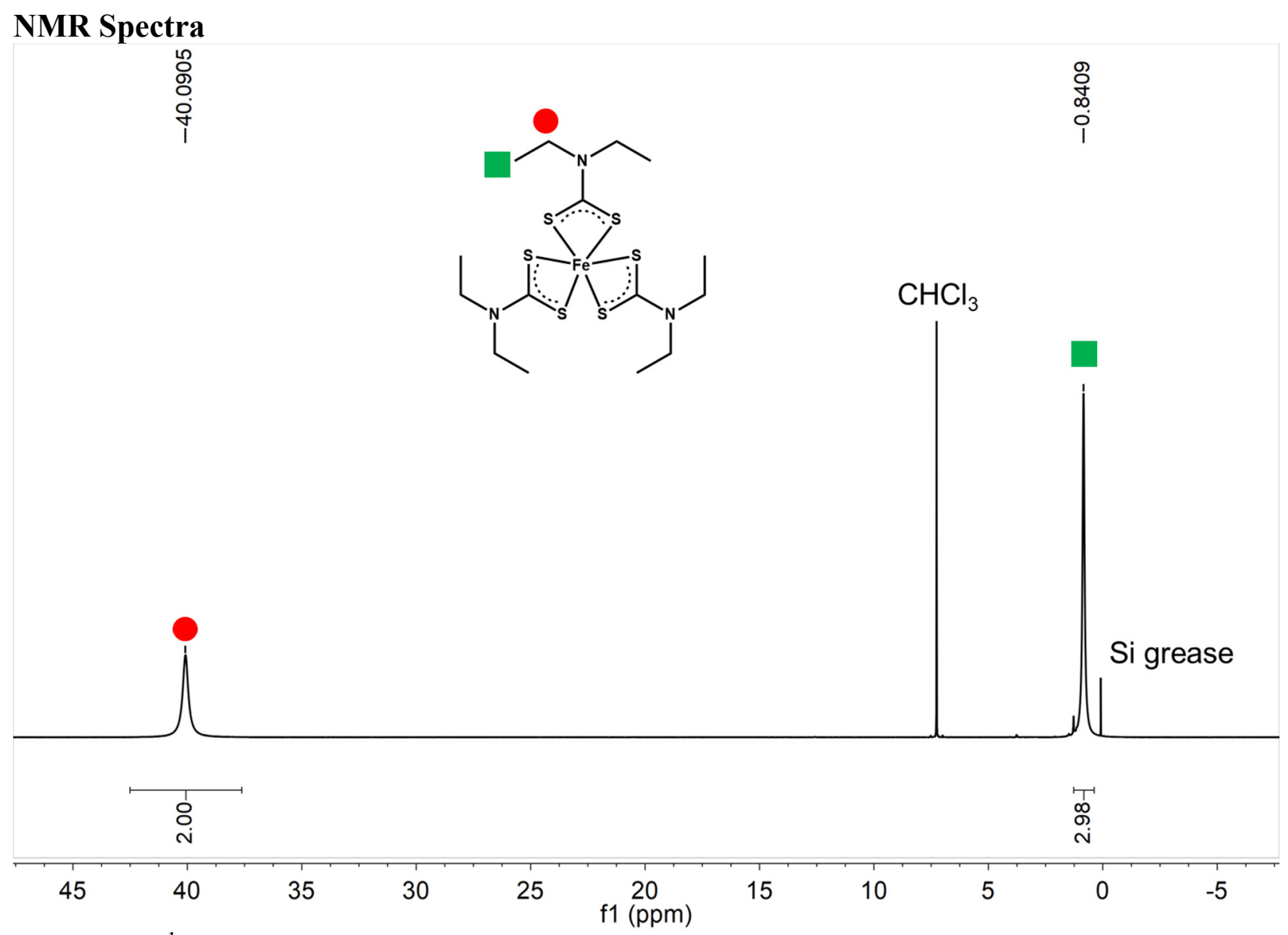

Figure S1: ${ }^{1} \mathrm{H}$ NMR spectrum of $\mathrm{Fe}(\mathrm{DEDTC})_{3}$ in $\mathrm{CDCl}_{3}$. 


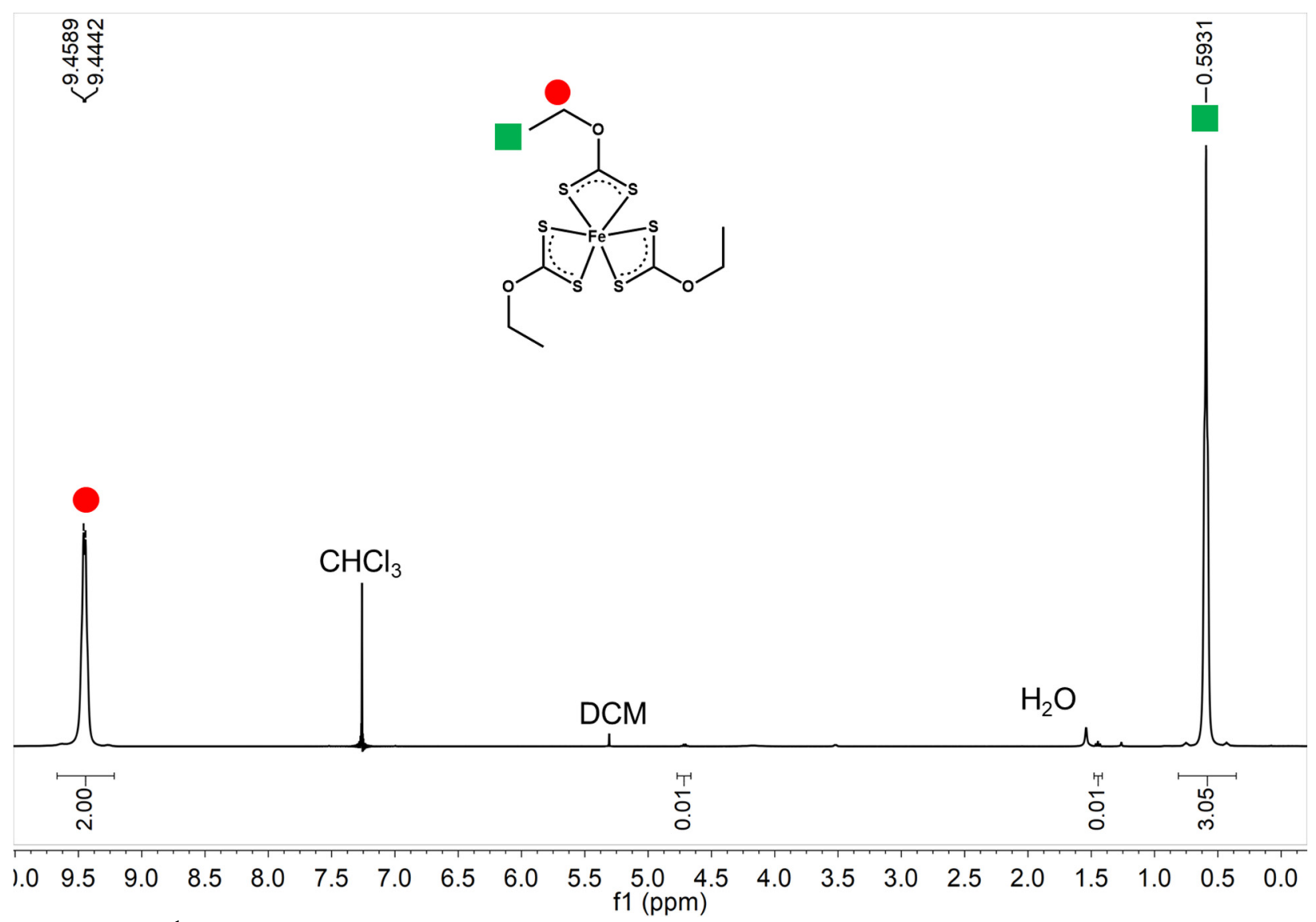

Figure S2: ${ }^{1} \mathrm{H}$ NMR spectrum of $\mathrm{Fe}(\mathrm{EX})_{3}$ in $\mathrm{CDCl}_{3}$. Small unlabeled peaks are due to traces of free ligand and methanol. 
Scanning Electron Microscopy

a)

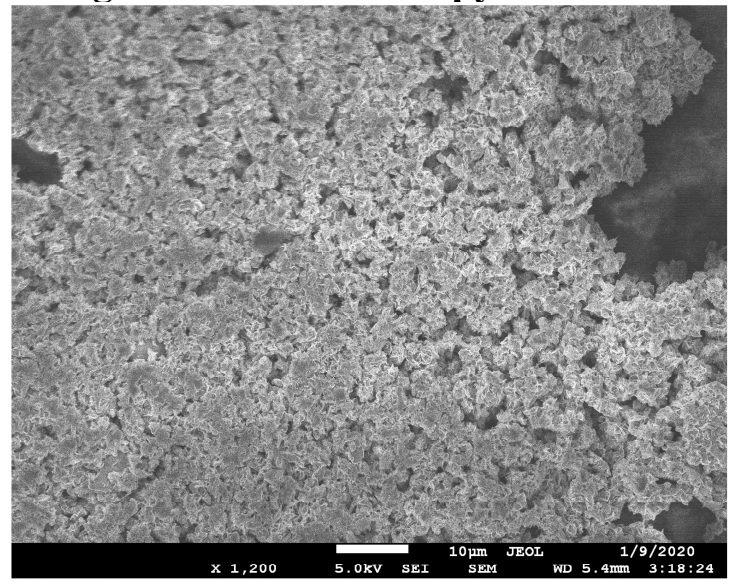

c)

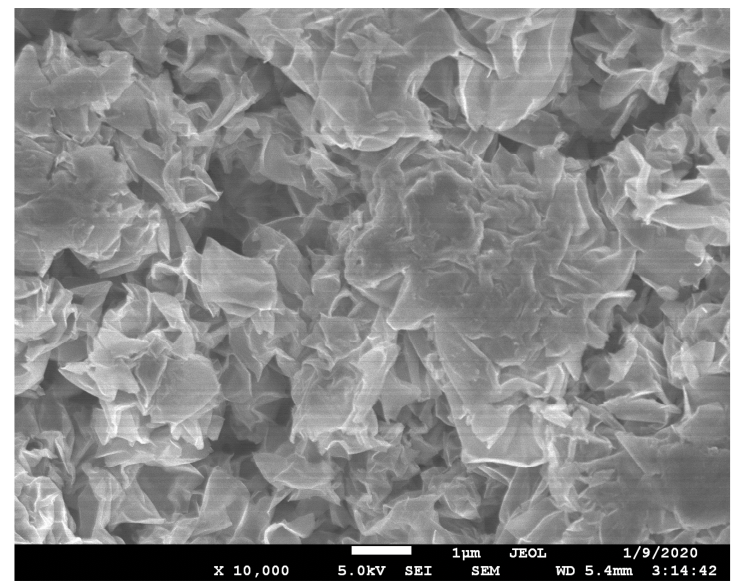

b)

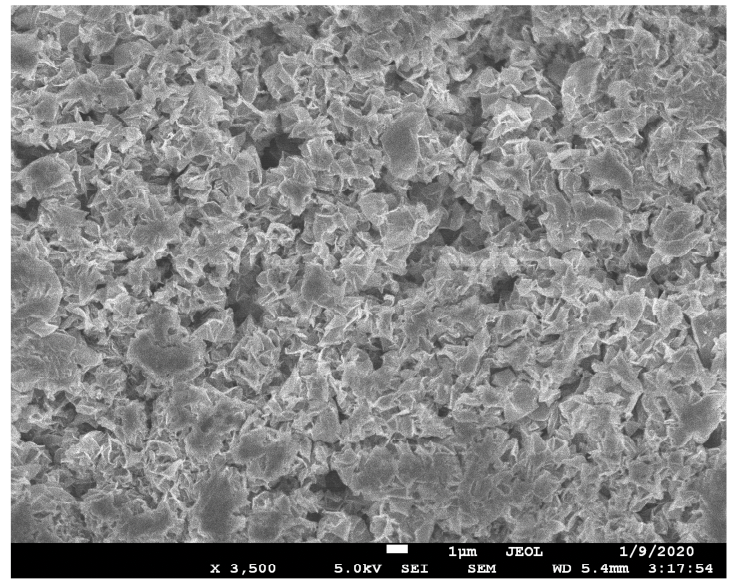

d)

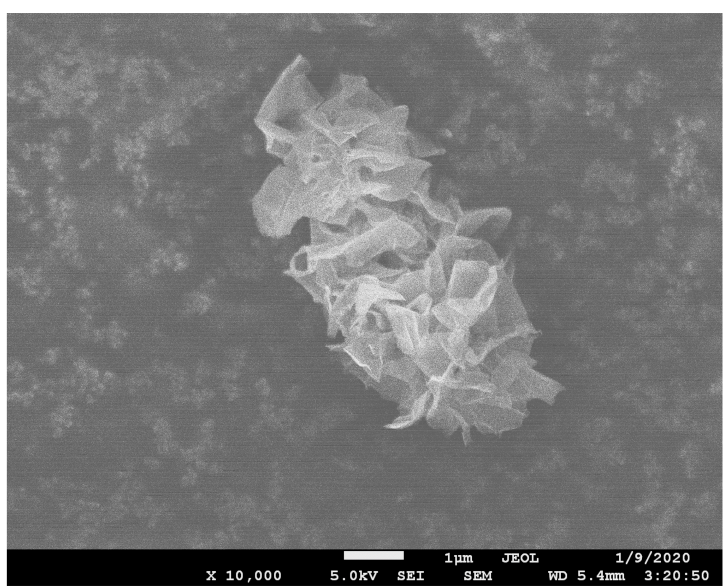

Figure S3. Representative SEM images of aggregates (a-b) and an isolated flake (d) of 1-Li. 
X-ray Powder Diffraction Measurements

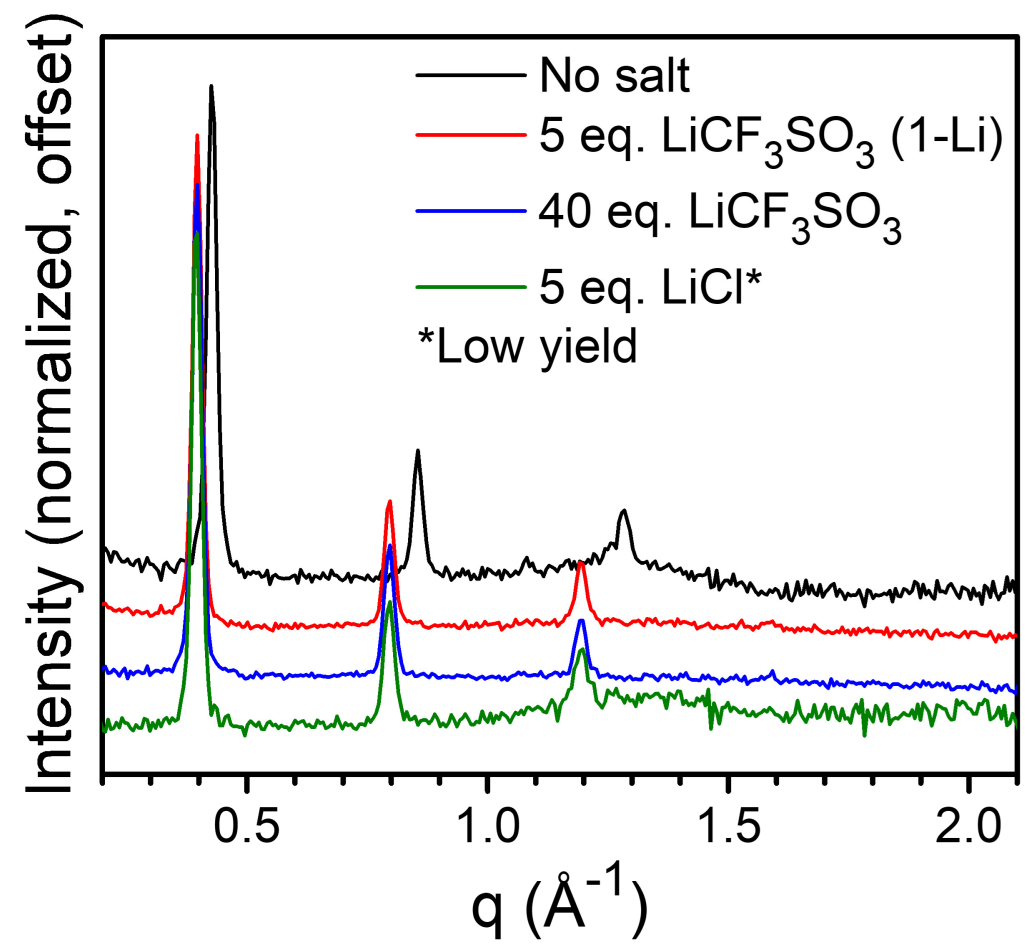

Figure S4: XRPD patterns of materials synthesized from $\mathrm{Fe}(\mathrm{EX})_{3}$ with different salt additives (all measured wet as suspensions in DMF).

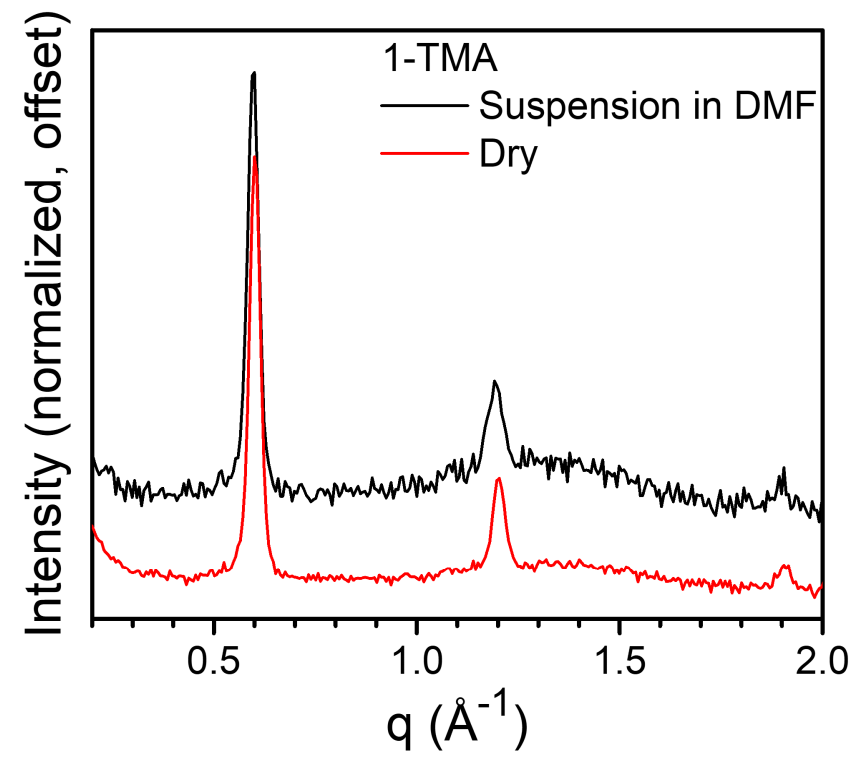

Figure S5: XRPD patterns of 1-TMA wet with DMF and dried. 


\section{X-ray Fluorescence Data}

$\mathrm{cps} / \mu \mathrm{A}$

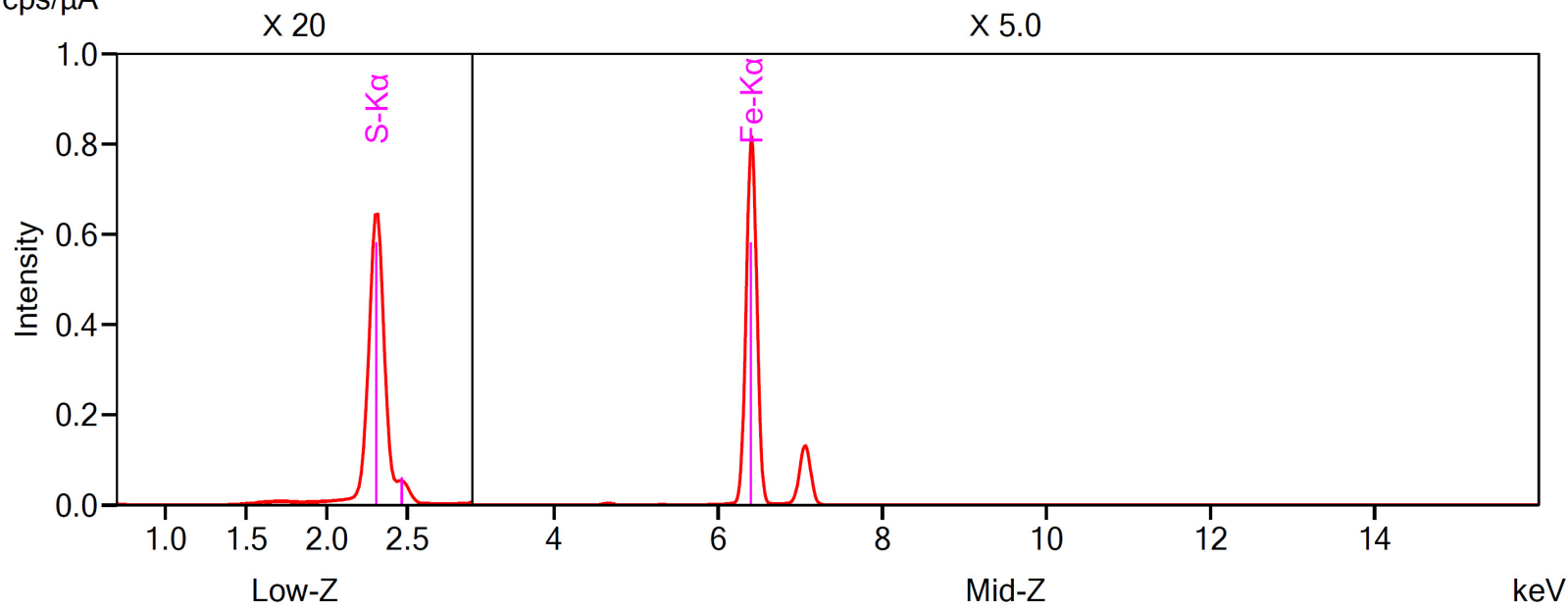

Figure S6: Representative XRF spectrum of 1-Li.

\section{X-ray Absorption (XAS) Data and Fits}

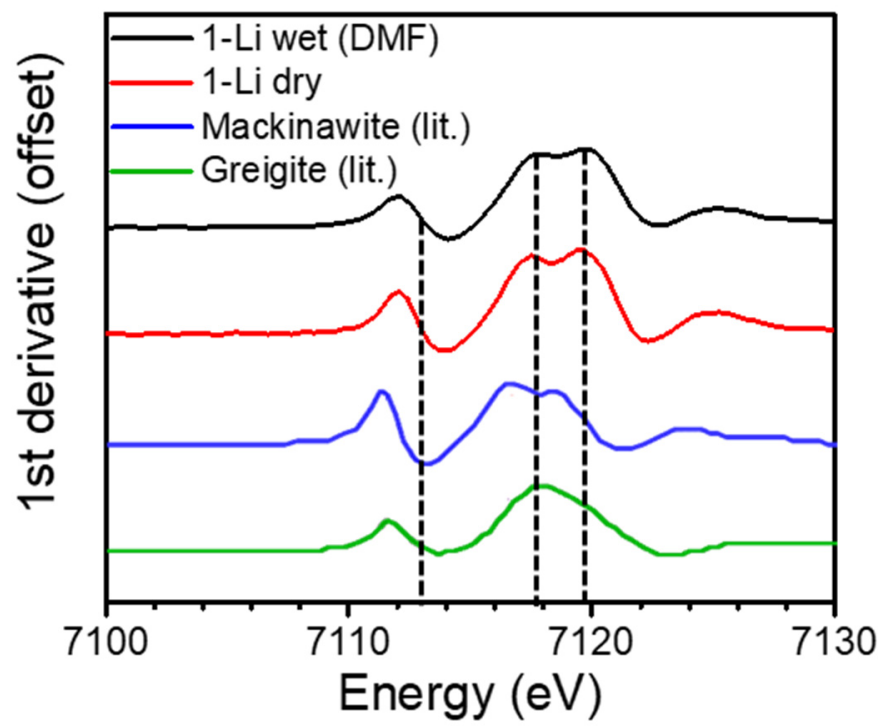

Figure S7: Comparison of Fe K-edge XANES (first derivative) from 1-Li to literature data for mackinawite and greigite. Literature spectra adapted from Jeong et al., Water Res. 2013, 47, 66396649. 


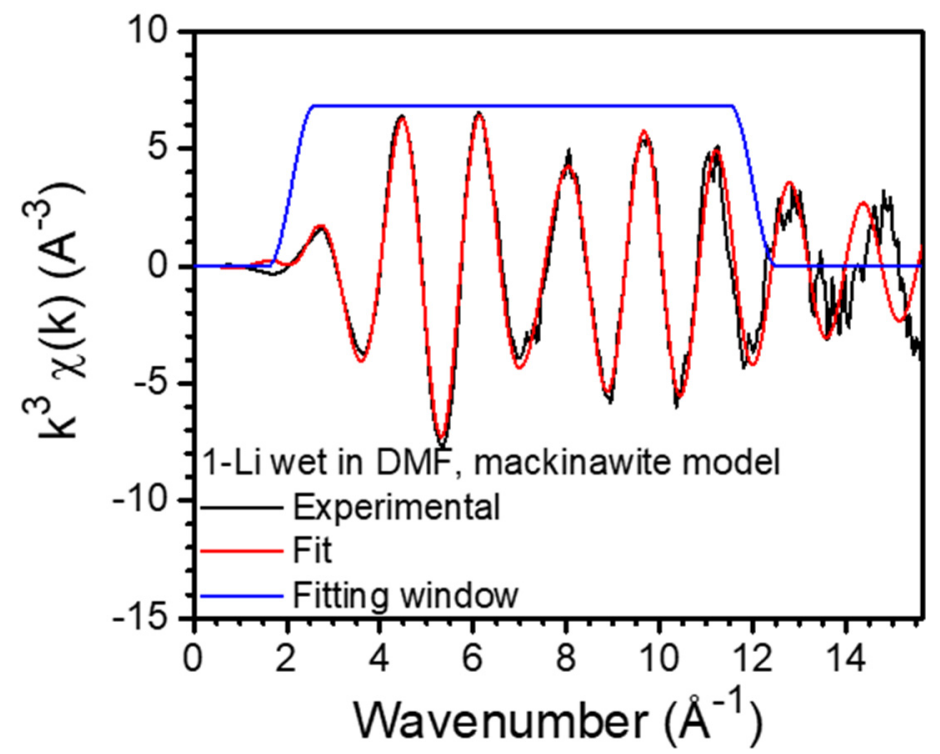

Figure S8: EXAFS data from 1-Li (wet in DMF) with fit to mackinawite model presented in kspace.

a)

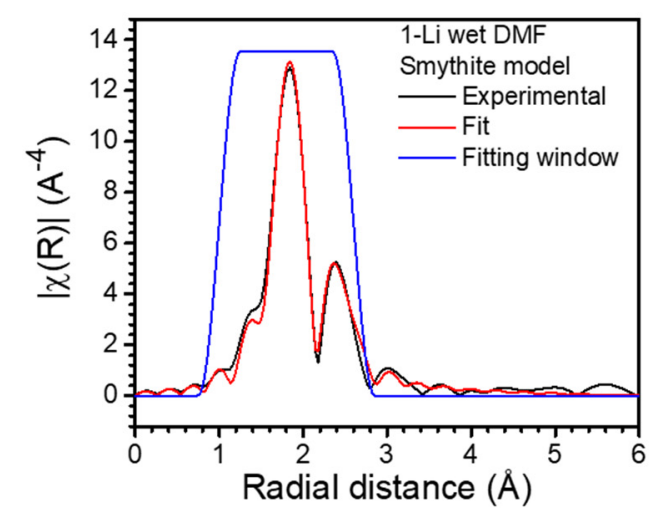

b)

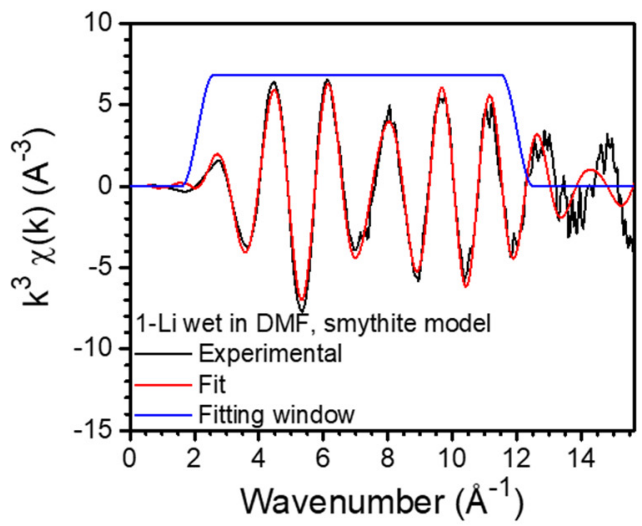

Figure S9: EXAFS data from 1-Li (wet in DMF) with a) R-space and b) k-space fits to smythite model. 
Table S1: EXAFS fitting parameters for 1-Li (wet in DMF) using structural models from mackinawite and smythite crystal structures.

\begin{tabular}{cccccc}
\hline Mackinawite model & $\mathrm{N}$ & $\mathrm{R}(\AA)$ & $\sigma_{2}\left(\AA^{2}\right)$ & R-factor & Reduced chi-square \\
\hline $\mathrm{Fe}_{1}-\mathrm{S}$ & 4 & $2.257(6)$ & $0.0028(8)$ & 0.0079 & 484 \\
$\mathrm{Fe}_{1}-\mathrm{Fe}_{2}$ & 4 & $2.71(2)$ & $0.012(2)$ & \\
Independent points $=9.8$, number of variables $=6, \Delta \mathrm{E}_{0}=1.3(7) \mathrm{eV}, \mathrm{S}_{0}{ }^{2}=0.672$, fitting range $\mathrm{k}=2.1-12 \AA^{-1}$ and $\mathrm{R}$ \\
$=1-2.6 \AA$, $\mathrm{k}$ weights $=1,2,3$
\end{tabular}

\begin{tabular}{ccccc} 
Smythite model & & & & \\
\hline $\mathrm{Fe}_{1}-\mathrm{S}$ & 6 & $2.265(8)$ & $0.004(1)$ & 0.0097 \\
$\mathrm{Fe}_{1}-\mathrm{Fe}_{2}$ & 2 & $\begin{array}{c}2.72(2) \\
0.003(2)\end{array}$ & & 802
\end{tabular}

Independent points $=9.8$, number of variables $=6, \Delta \mathrm{E}_{0}=1.6(8) \mathrm{eV}, \mathrm{S}_{0}{ }^{2}=0.496$, fitting range $\mathrm{k}=2.1-12 \AA^{-1}$ and $\mathrm{R}$ $=1-2.6 \AA$, $\mathrm{k}$ weights $=1,2,3$

a)

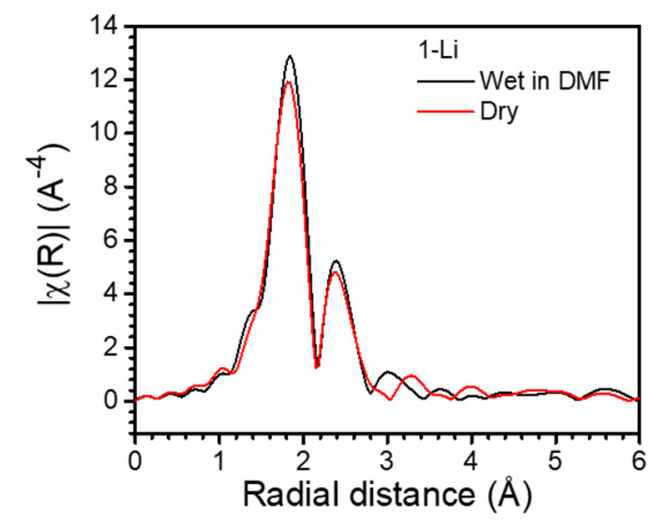

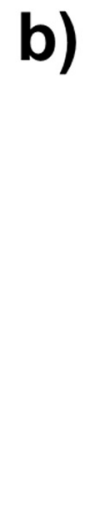

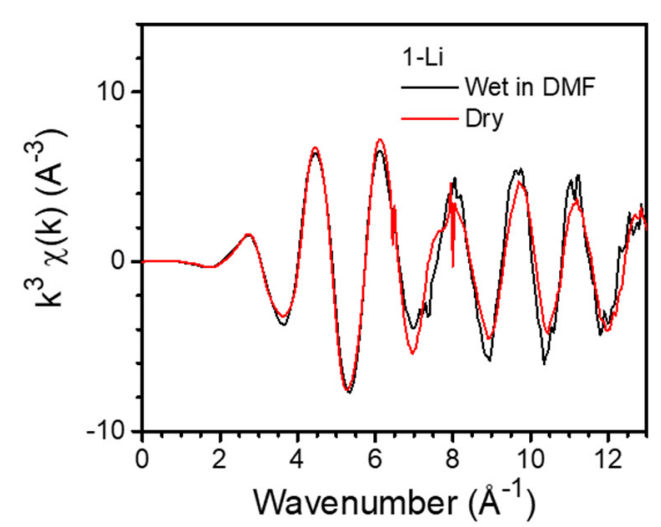

Figure S10: Comparison of EXAFS data from wet (DMF) and dry samples of 1-Li in a) R-space and b) k-space. 
Thermogravimetric Analysis (TGA)

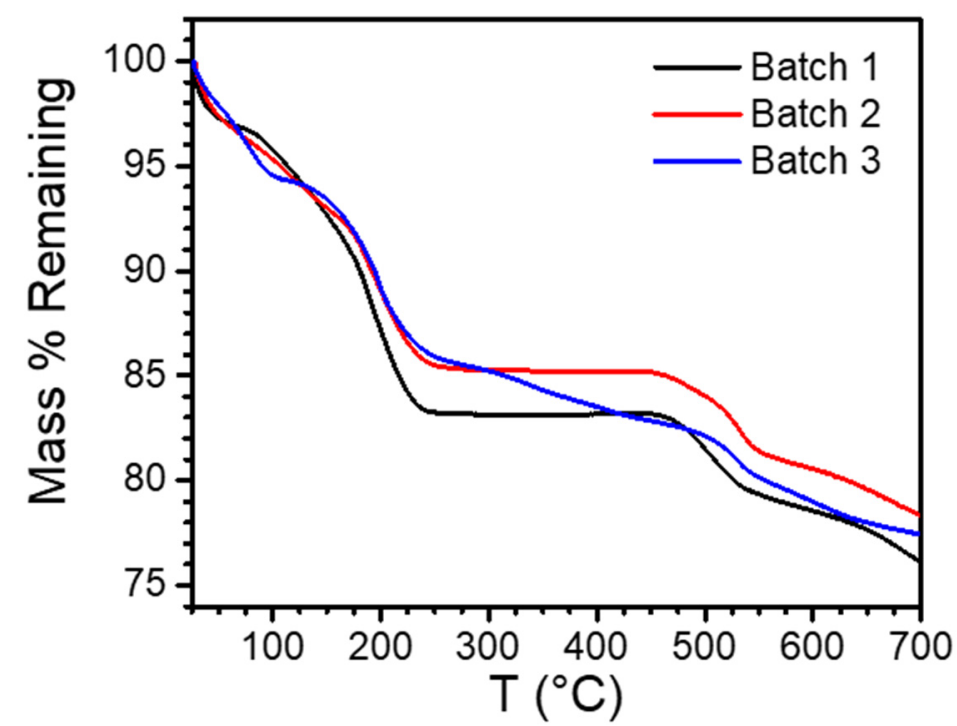

Figure S11: Thermogravimetric analysis data for three batches of 1-Li, measured under $\mathrm{N}_{2}$ with a $5{ }^{\circ} \mathrm{C} / \mathrm{min}$ ramp rate. 


\section{UV-visible-NIR Spectroscopy}

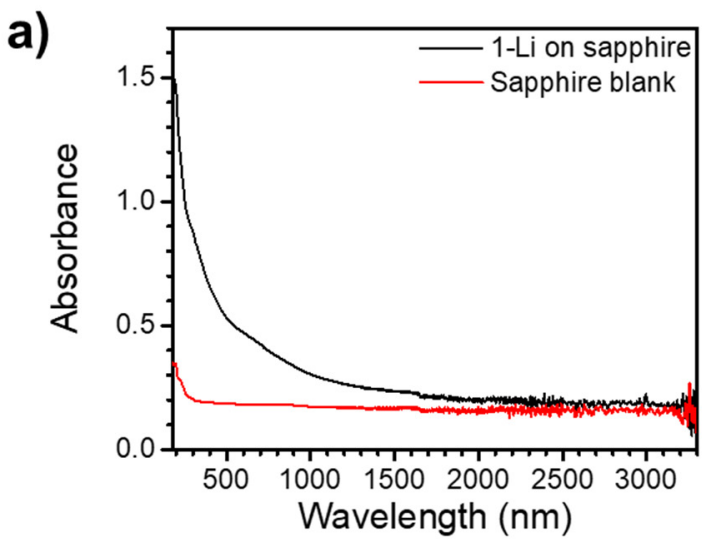

c)

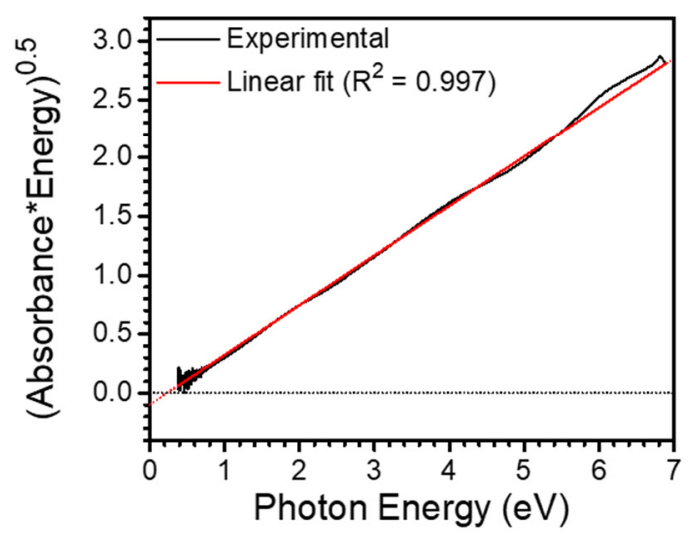

b)

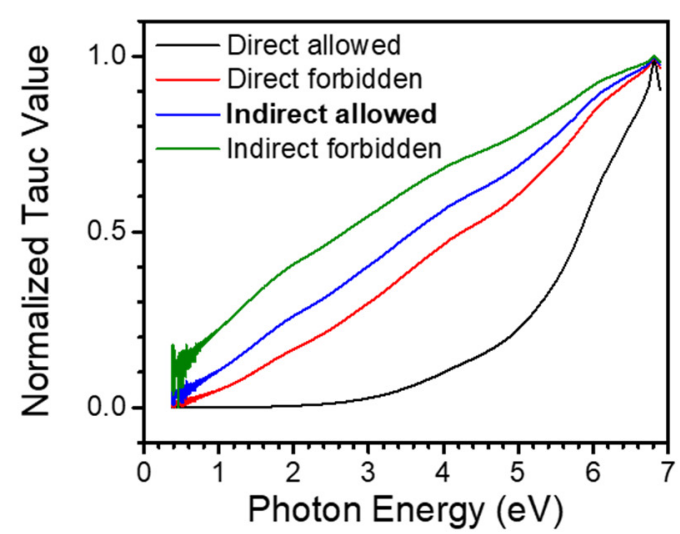

d)

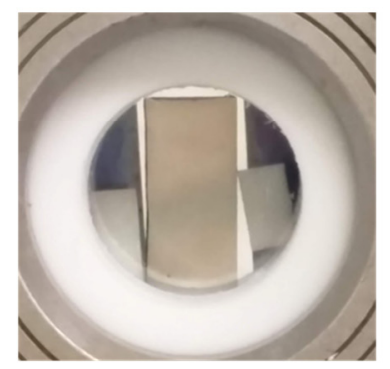

Figure S12: UV-visible-NIR absorption data for 1-Li. a) UV-visible-NIR absorption spectrum of 1-Li on sapphire (0001) and sapphire blank. b) Comparison of Tauc plots assuming different types of transitions. The indirect allowed transition produces the most linear plot. c) Tauc plot for indirect allowed transition with linear fit corresponding to $\mathrm{E}_{\mathrm{g}}=0.23 \mathrm{eV}$. Dotted lines highlight the $\mathrm{X}$-axis and the linear fit as a visual guide. d) Photograph of 1-Li on sapphire (0001) sample (center) in holder. 


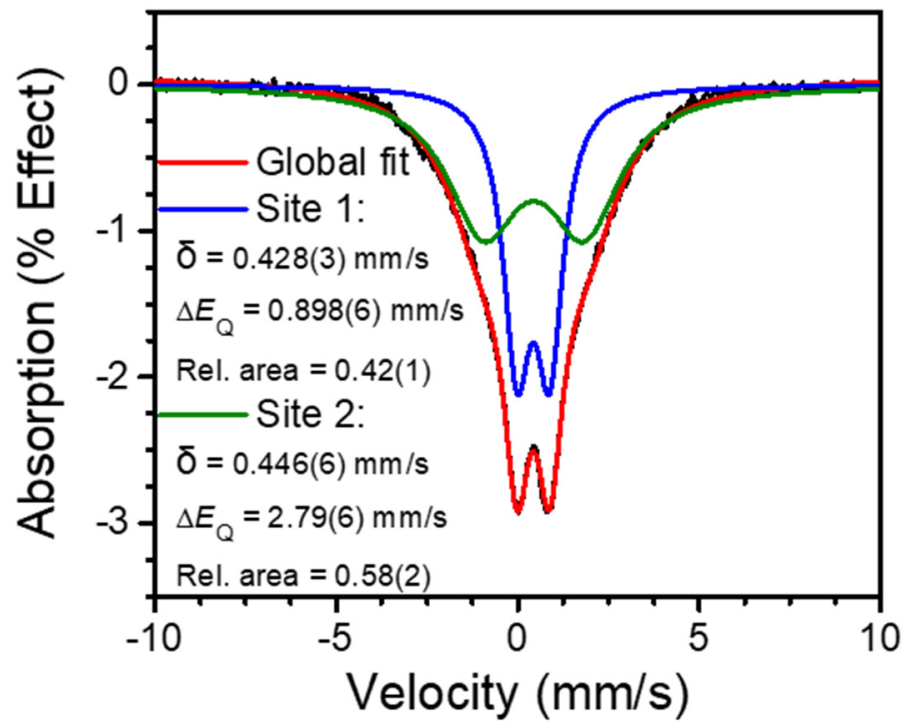

Figure S13: ${ }^{57} \mathrm{Fe}$ Mössbauer spectrum of 1-Li collected at $80 \mathrm{~K}$ with fit to a two site model.

Table S2: Mössbauer fitting parameters.

\begin{tabular}{ccc}
\hline Parameter & Site 1 & Site 2 \\
\hline Isomer shift $(\delta)$ & $0.428(3) \mathrm{mm} / \mathrm{s}$ & $0.446(4) \mathrm{mm} / \mathrm{s}$ \\
Quadrupole splitting $\left(\Delta E_{\mathrm{Q}}\right)$ & $0.898(6) \mathrm{mm} / \mathrm{s}$ & $2.79(6) \mathrm{mm} / \mathrm{s}$ \\
Relative area & $0.42(1)$ & $0.58(2) \mathrm{mm} / \mathrm{s}$ \\
Gaussian broadening, FWHM & $0.90(2) \mathrm{mm} / \mathrm{s}$ & $2.43(3) \mathrm{mm} / \mathrm{s}$ \\
\hline
\end{tabular}




\section{IR Spectroscopy}

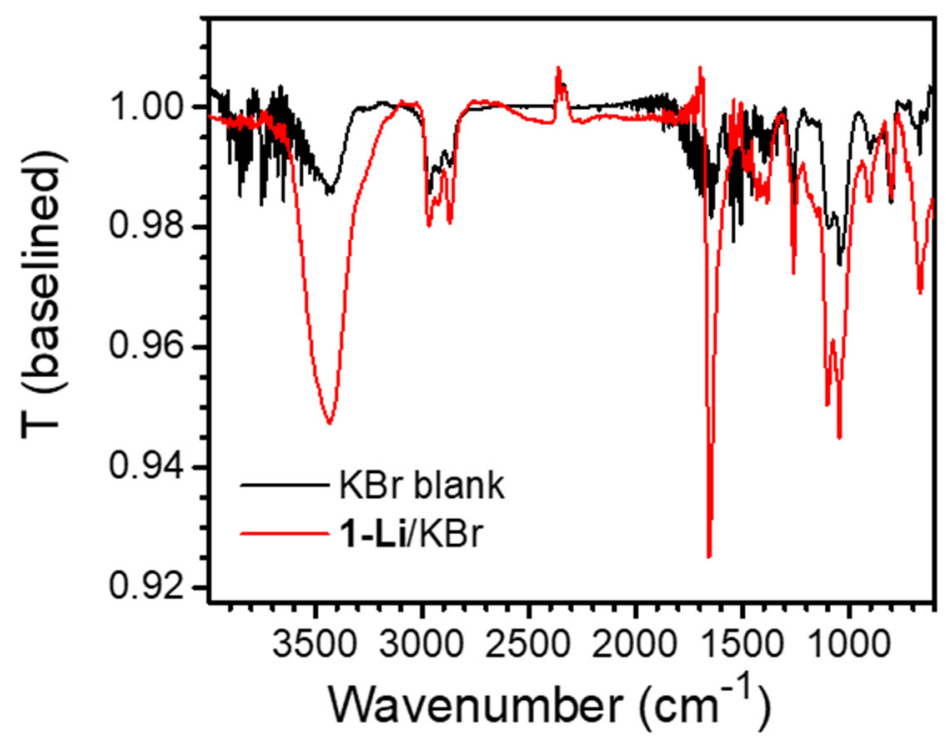

Figure S14: FTIR spectrum of 1-Li prepared as a $\mathrm{KBr}$ pellet.

\section{Electrochemical Measurements}

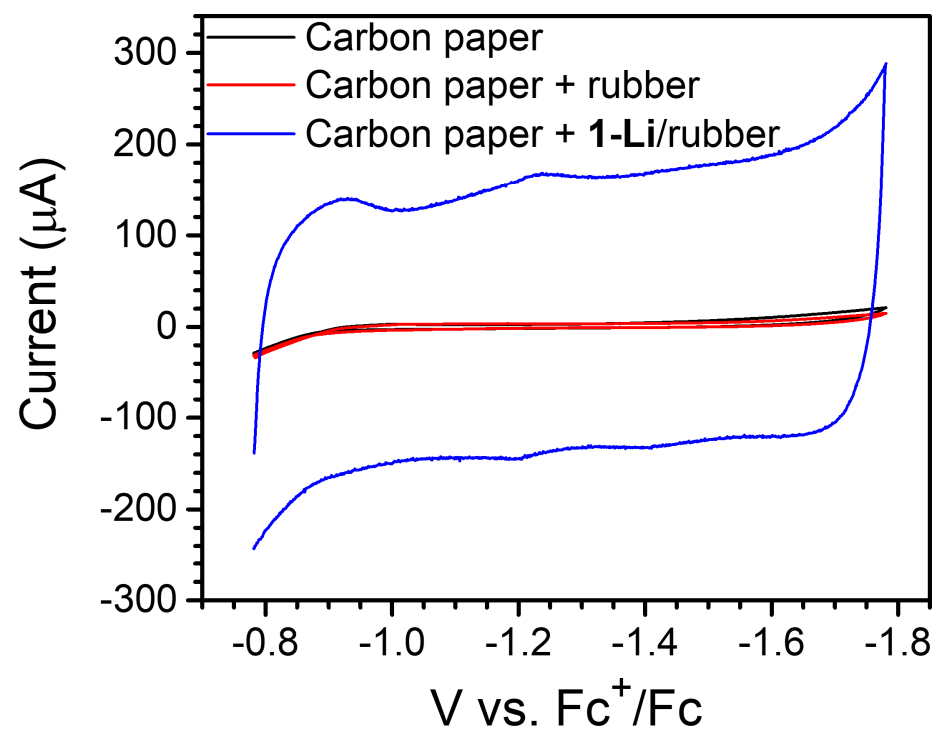

Figure S15. Cyclic voltammograms $\left(1 \mathrm{mV} / \mathrm{s}, 0.1 \mathrm{M} \mathrm{LiCF}_{3} \mathrm{SO}_{3}\right.$ in $\left.\mathrm{DMF}\right)$ of carbon paper electrode coated with $\mathbf{1 - L i}+10 \%$ rubber slurry and control electrodes. 


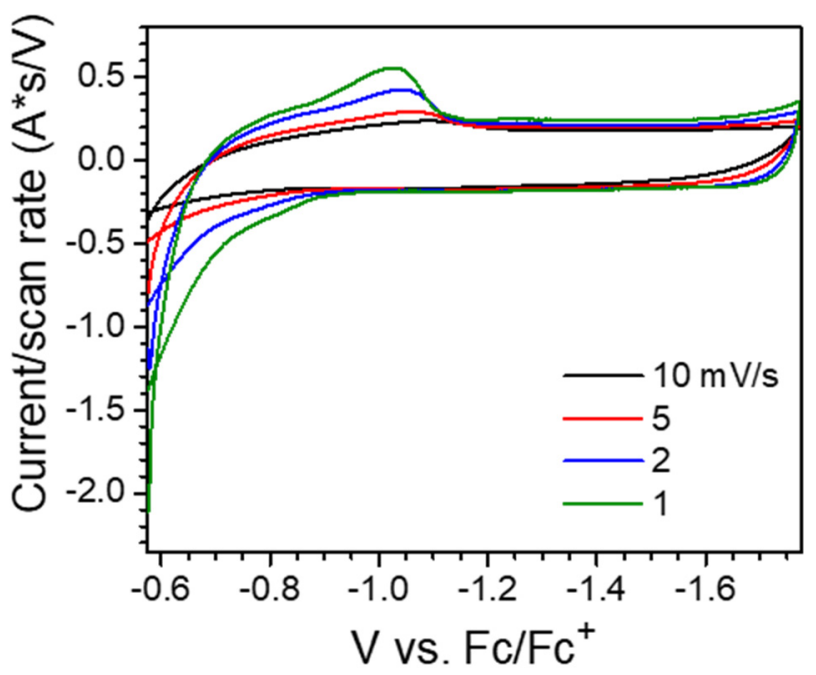

Figure S16: Cyclic voltammetry data for 1-Li composite electrode in $0.1 \mathrm{M} \mathrm{LiCF}_{3} \mathrm{SO}_{3} / \mathrm{DMF}$ showing Faradaic features. Data is plotted as current/scan rate, which for a capacitor gives the capacitance in Farads. Pseudocapacitive features should show no scan rate dependence, while Faradaic features should decrease at higher scan rates.

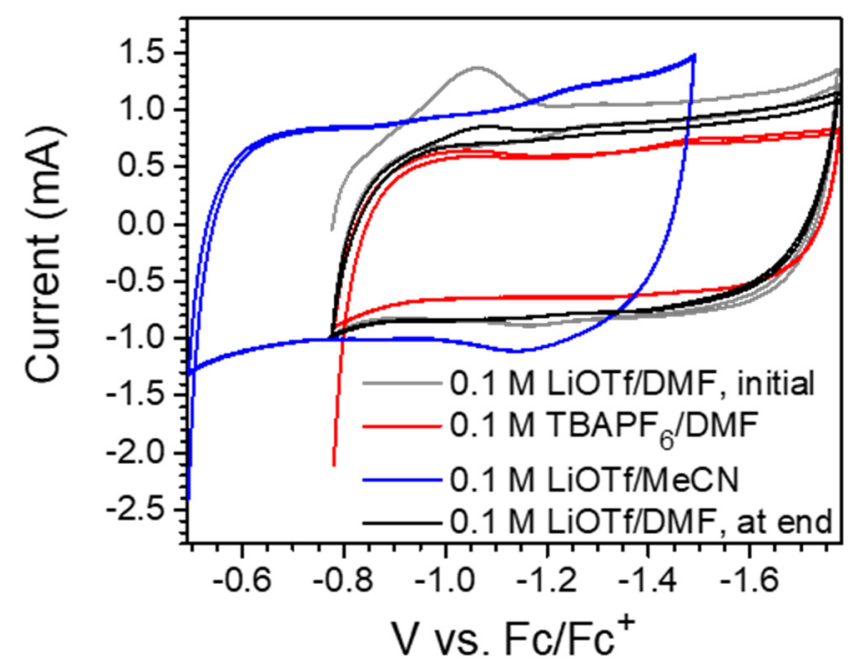

Figure S17: Cyclic voltammograms of the same 1-Li composite electrode in different electrolytes, measured at $10 \mathrm{mV} / \mathrm{s}$. $\mathrm{LiOTf}=\mathrm{LiCF}_{3} \mathrm{SO}_{3}$. 


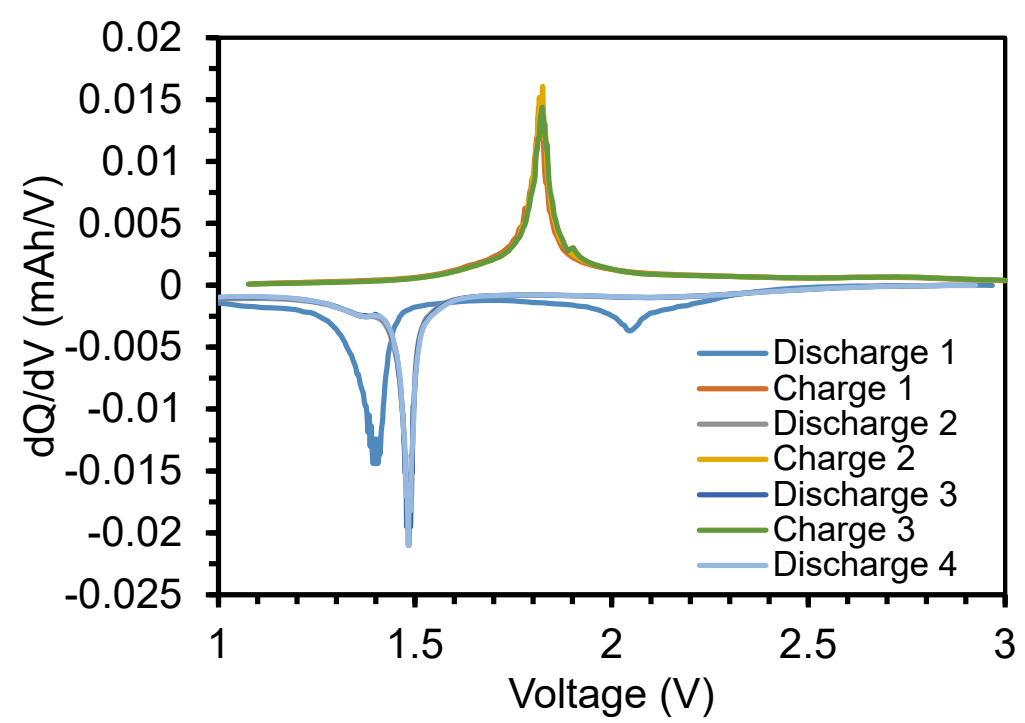

Figure S18: dQ/dV plot for 1-Li lithium ion cathode half cell tests at $0.1 \mathrm{C}$.

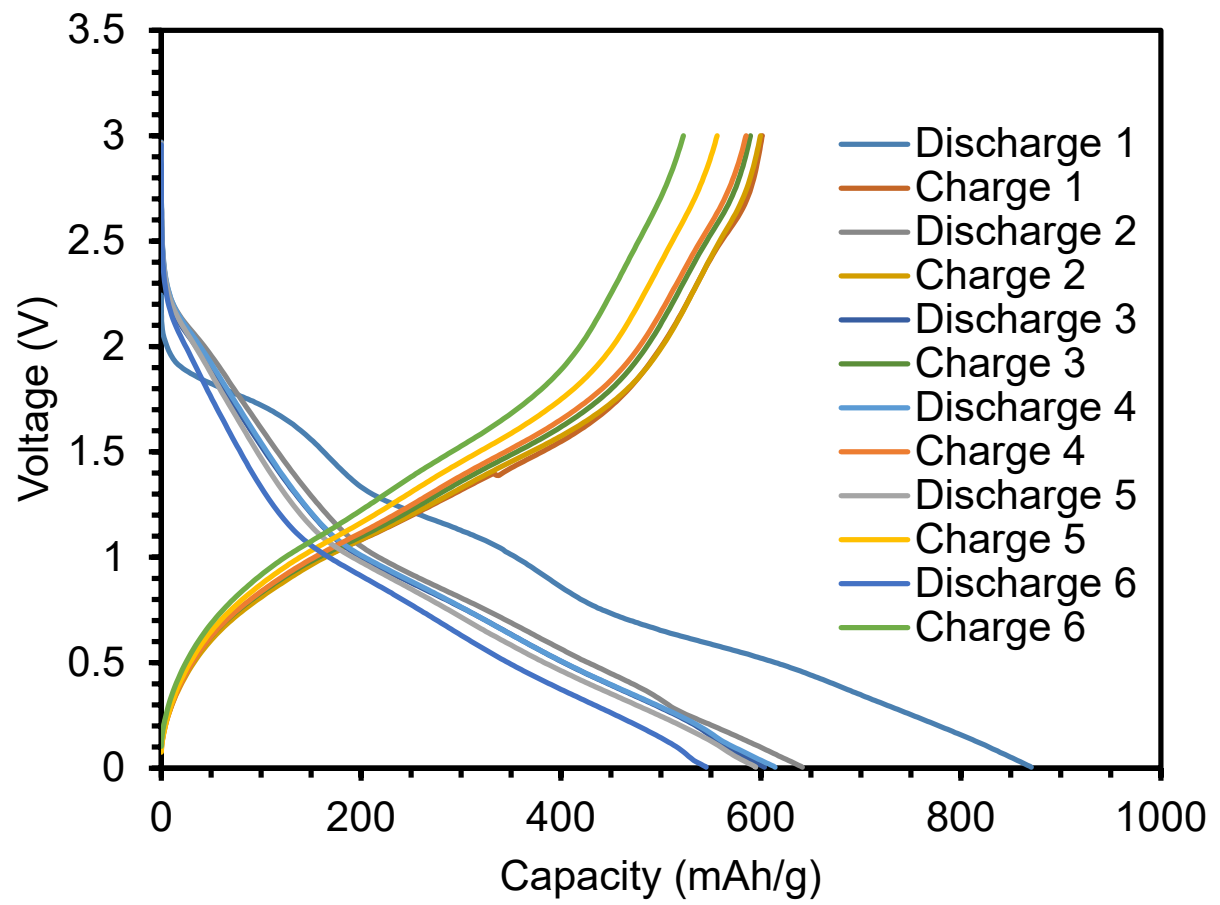

Figure S19: Charge/discharge curves for 1-Li sodium ion cathode half cell tests. $\mathrm{V}=0.005-3.0$ $\mathrm{V}$ vs. $\mathrm{Na}, \mathrm{I}=30 \mathrm{~mA} / \mathrm{g}, 1 \mathrm{M} \mathrm{NaPF} 6$ in $\mathrm{EC} / \mathrm{DEC}+2 \mathrm{w} \% \mathrm{FEC}$. 


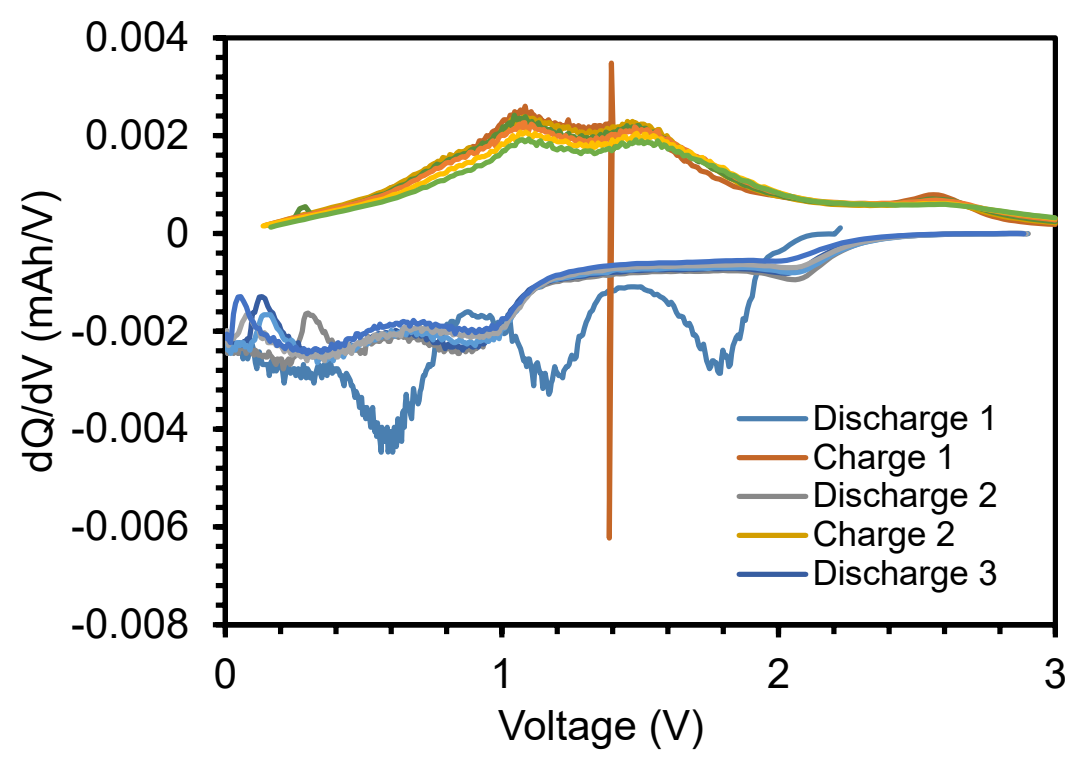

Figure S20: dQ/dV plot for 1-Li sodium ion cathode half cell tests.

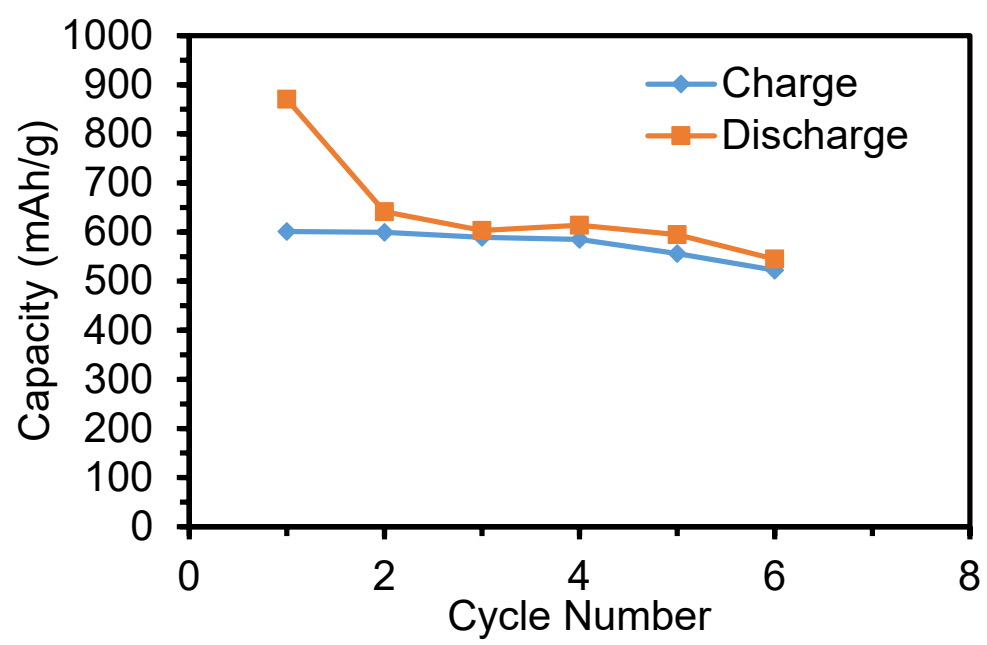

Figure S21: Cycling stability of 1-Li sodium ion cathode in half cell tests. 


\section{New Lamellar Iron Sulfide Materials}

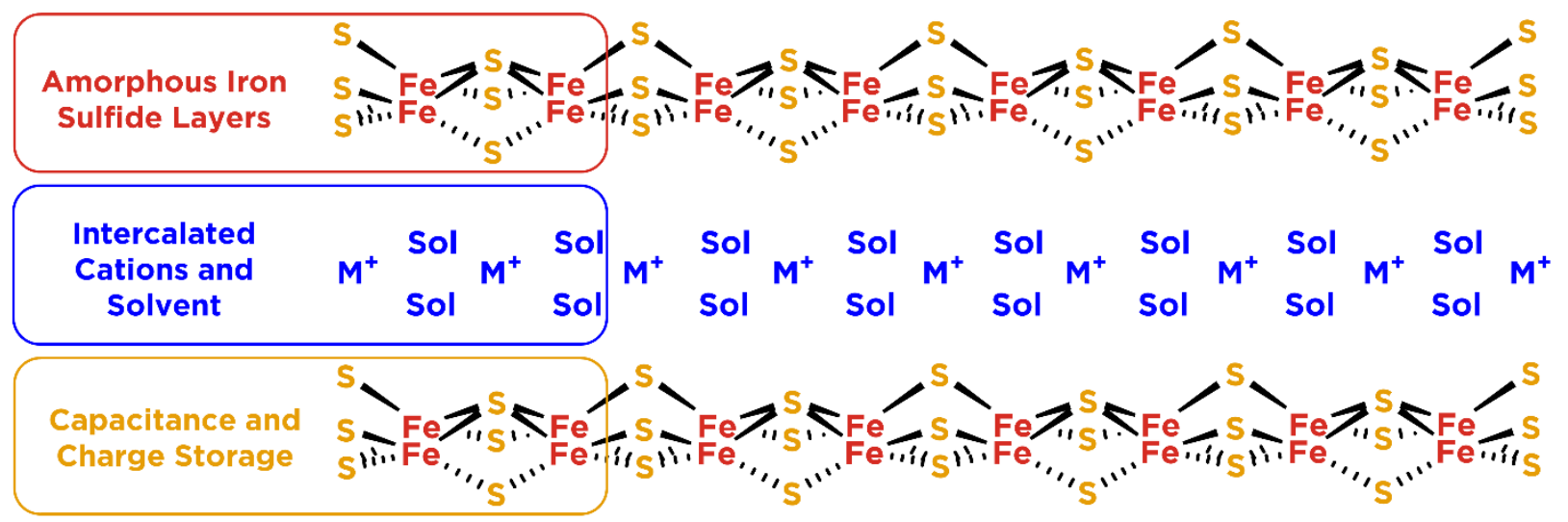

A new class of layered iron sulfide materials offers tunable composition and properties for electrochemical energy storage. 
